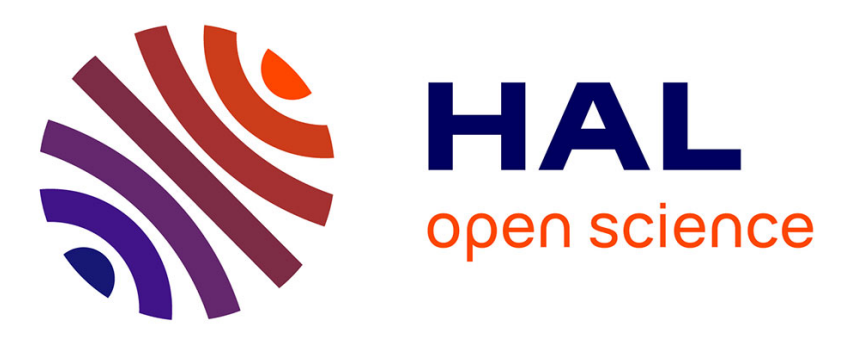

\title{
Montmorillonite colloids: I. Characterization and stability of dispersions with different size fractions
}

Knapp Karin Norrfors, Muriel Bouby, Stephanie Heck, Nicolas Finck, Remi Marsac, Thorsten Schäfer, Horst Geckeis, Susanna Wold

\section{- To cite this version:}

Knapp Karin Norrfors, Muriel Bouby, Stephanie Heck, Nicolas Finck, Remi Marsac, et al.. Montmorillonite colloids: I. Characterization and stability of dispersions with different size fractions. Applied Clay Science, 2015, 114, pp.179 - 189. 10.1016/j.clay.2015.05.028 . hal-01904321

\section{HAL Id: hal-01904321 \\ https://hal.science/hal-01904321}

Submitted on 24 Oct 2018

HAL is a multi-disciplinary open access archive for the deposit and dissemination of scientific research documents, whether they are published or not. The documents may come from teaching and research institutions in France or abroad, or from public or private research centers.
L'archive ouverte pluridisciplinaire HAL, est destinée au dépôt et à la diffusion de documents scientifiques de niveau recherche, publiés ou non, émanant des établissements d'enseignement et de recherche français ou étrangers, des laboratoires publics ou privés. 
1 Montmorillonite colloids. I: Characterization and stability of dispersions with different size fractions

Knapp Karin Norrfors*a,b, Muriel Bouby ${ }^{\mathrm{a}}$, Stephanie Heck ${ }^{\mathrm{a}}$, Nicolas Finck ${ }^{\mathrm{a}}$, Rémi Marsac ${ }^{\mathrm{a}}$, Thorsten Schäfer ${ }^{\mathrm{a}}$, Horst Geckeis ${ }^{\mathrm{a}}$ and Susanna Wold

a: Karlsruhe Institute of Technology (KIT), Institute for Nuclear Waste Disposal (INE), P.O. Box 3640, D-760 21 Karlsruhe, Germany

b: School of Chemical Science and Engineering, Applied Physical Chemistry, KTH Royal Institute of Technology, Teknikringen 30, SE-100 44 Stockholm, Sweden

*Corresponding author. E-mail: norrfors@kth.se (K.K. Norrfors) Tel: +46 8 7909279. Fax: +46 87908772.

\section{Abstract}

Bentonite is planned to be used as a technical barrier in the final storage of spent nuclear fuel and high level vitrified waste. In contact with ground water of low ionic strength, montmorillonite colloids may be released from the bentonite buffer and thereby enhance the transport of radionuclides (RNs) sorbed. In the present case, clay colloids represent aggregates of several clay mineral layers. It is of major importance to determine RN sorption properties for different sizes of montmorillonite aggregates, since size fractionation may occur during particle transport in natural media. In this study, a protocol for size fractionation of clay aggregates is developed, by sequential and direct centrifugation, in presence and absence of organic matter. Seven colloidal fractions of different mean aggregate sizes are obtained ranging, when considering the mean equivalent hydrodynamic sphere diameter (ESD), from $\sim 960 \mathrm{~nm}$ down to $\sim 85 \mathrm{~nm}$. Applying mathematical treatments (Jennings and Parslow, 1988) and approximating the clay aggregates to regular disc-shaped stacks of clay mineral sheets, results in mean surface diameters varying from $\sim 1.5 \mu \mathrm{m}$ down to $\sim 190 \mathrm{~nm}$. All these colloidal fractions are characterized by XRD, IC and ICP-OES where they are found 
to have the same chemical composition. The number of edge sites (aluminol and silanol) is estimated (in mol $/ \mathrm{kg}$ ) for each colloidal fraction according to (Tournassat et al., 2003). It is calculated from the mean particle sizes obtained from AsFlFFF and PCS measurements, where the clay aggregates are approximated to regular disc-shaped stacks of clay mineral sheets. The estimated number of edge sites varies significantly for the different clay dispersions. In addition, stability studies using the various clay colloidal fractions are performed by addition of $\mathrm{NaCl}, \mathrm{CaCl}_{2}$ or $\mathrm{MgCl}_{2}$, in presence or absence of organic matter, where no difference in stability is found.

\section{Keywords}

Montmorillonite colloids, characterization, size separation, number of edge sites, nuclear waste disposal, colloidal stability

\section{Introduction}

In Swedish and Finnish repository designs (SKB, 2010; Vieno and Ikonen, 2005), high level nuclear waste is foreseen to be placed in massive metal canisters, surrounded by a large volume of natural or compacted bentonite as a barrier. The functionality of the clay is primarily to stabilize the canister in case of movements in the bedrock and to seal small fractures in the vicinity of the canister. The barrier is planned to prevent corrosive elements from the surrounding, such as sulfide, thiosulfate and polythionates (Macdonald and SharifiAsl, 2011) to come in contact with the canister. In case of canister failure, the barrier should retard radionuclides (RNs) present in the spent nuclear fuel to be transported through the geosphere towards the biosphere. Due to its high swelling pressure, cation exchange capacity and retention properties, bentonite has an excellent buffer capacity (Karnland et al., 2006). The main mineral component in bentonite is montmorillonite, an Al-rich smectite. Smectites are intrinsically small particles, whereby they can be of colloidal sizes (i.e. particles of $1 \mathrm{~nm}$ - 
$1 \mu \mathrm{m}$ in at least one dimension in dispersion (Stumm, 1993)). In this work, the term clay colloids refer to aggregates, consisting of stacks of several clay mineral layers.

Over the estimated lifetime of the storage (i.e. 1 million years) in northern countries such as Sweden and Finland (SKB, 2010), cycles of glaciations can be expected. In the worst case scenario expected in Sweden, a large amount of glacial melt water will be transported through fractures in the bedrock, down to repository depth and displace the old ground water that has equilibrated with mineral surfaces for a very long time. Glacial melt water has a chemical composition with low ionic strength, different from the original porewater. The chemical composition of future glacial melt water is assumed to be similar to glacial melt waters of today. It can be simulated by water types of $\mathrm{pH} 8-9$ and low ionic strength, i.e. $5 \cdot 10^{-4} \mathrm{M}$ in the worst case scenario cited above (Brown, 2002). The montmorillonite colloid stability is known to increase with decreasing ionic strength, as demonstrated in several laboratories and field experiments studies over a few months' timeframe (Geckeis et al., 2004; Missana et al., 2003; Schäfer et al., 2012) and can also be calculated from the DVLO-theory (Liu et al., 2008). In contact with glacial melt water, the bentonite barrier may release montmorillonite colloids that can be transported away from the barrier through the geosphere. In case of large mass loss, the buffer functionality will be endangered. Also, in the case of a canister failure, the transport of RNs can be enhanced, when transported by mobile montmorillonite colloids (Möri et al., 2003).

Physically, colloid mobility depends strongly on the geometry of the fractures in the bedrock, where fracture size distribution, surface roughness and surface charge are the most important characteristics (Darbha et al., 2010; Filby et al., 2008). Chemically, the colloid mobility is influenced by the mineral composition of the fracture filling material (FFM) and the pore water matrix. The colloid mobility is also dependent on physical and chemical properties of the clay aggregates themselves, i.e. the size heterogeneity, mineral composition and surface 
charge. The physical and chemical properties of the bedrock are specific for each fracture, though in general a separation of particles according to their size during transport is expected in most systems. In a clean fracture system, i.e. fractures with low amount of FFM, and with a high water velocity, a laminar flow is expected and transport of all colloid sizes is expected more or less equally due to their ability to be transported with the water flow (Huber et al., 2012). In contrary, if the fracture contains a larger amount of FFM, it will act as a porous material, where the larger particles can be transported faster as a result of size exclusion effects, sticking, clogging etc. Due to the possible particle size separation in bedrock fractures, the size of the montmorillonite aggregates produced and their stability are important parameters for RN transport. The thermodynamic and kinetic strength of $\mathrm{RN}$-colloid interaction determine the potential flux of radiotoxic waste components through the geosphere. In fact, those RNs being weakly bound to colloids or showing a relatively fast desorption from colloids will most likely not be carried by the montmorillonite colloids but will be sorbed by the mineral surfaces instead (Huber et al., 2014).

Simplified models of RN and clay colloid transport are currently used in safety assessments for estimating the $\mathrm{RN}$ transport, but presently they do not take into consideration the size heterogeneity of the clay aggregates (Vahlund and Hermansson, 2006). Consequently, one may wonder whether normalized sorption coefficients $\left(\mathrm{K}_{\mathrm{D}}\right)$ for $\mathrm{RNs}$ are valid expressions for quantifying RN-montmorillonite interactions, since the ratio is given for a mean particle size distribution and do not take into account polydispersity. An alternative, and perhaps better, expression for quantifying the sorption capacities of surface complexed RNs is to take into consideration the amount of edge sites in the colloidal dispersions. With this treatment, eventual size dependent differences will be taken into account. This is valid as long as the smaller particles are miniatures of the larger clay mineral particles, which may not be the case for nanosized particles (Bergaya et al., 2006). Note that this approach is not adapted for RNs 
sorbing by cation exchange (i.e. $\mathrm{Cs}^{+}, \mathrm{Sr}^{+}$etc.). Large differences in surface structure between larger and smaller clay particles may also be reflected in macroscopic properties, such as colloidal stability (Bessho and Degueldre, 2009). In modeling, transport of RNs may be

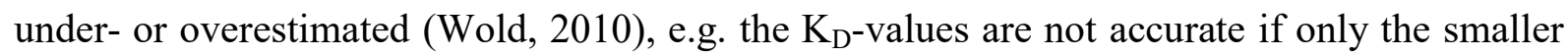
aggregates are transported and not the larger ones, or vice versa. Normalizing sorption capacity to the number of edge sites might improve transport calculations of RNs sorbed to different clay aggregate sizes. Furthermore, this treatment of $K_{D^{-}}$-values could be implemented to other systems, such as metal complexation to particles and their retardation in soils, as well as colloidal transport in soil and surface waters (Gao et al., 1997; Lee et al., 2001; Nakamaru and Uchida, 2008; Oliver et al., 2006). In addition to questionable normalization of sorption, i.e. $\mathrm{K}_{\mathrm{D}}$-values in transport modelling, there is a lack of sorption and desorption kinetic data for RNs onto different size fractions of montmorillonite aggregates which should be implemented for improved safety assessments calculations (Wold, 2010).

The aim of this work is to develop a method to separate montmorillonite aggregates into defined size fractions, to characterize these fractions and finally to determine if the mean clay aggregate size has any influence on the colloidal stability of montmorillonite. We describe the protocol used to obtain different size fractions, a protocol which may be applied to any type of clay dispersions. In addition, characterization of the different clay aggregate fractions such as mean size, concentration, and the chemical composition of the colloidal dispersions is presented. Furthermore, we describe stability studies performed on the colloidal fractions in order to investigate the influence of ions which can be present in glacial melt water $\left(\mathrm{Na}^{+}\right.$, $\mathrm{Ca}^{2+}, \mathrm{Mg}^{2+}$ (Missana et al., 2003)) or degraded organic matter (Bhatia et al., 2010). In separate studies (Norrfors et al., 2015), we investigate the RNs sorption/desorption behavior in presence of these clay aggregate size fractions.

\section{Material and Methods}




\subsection{Clay, organic matter, chemicals, synthetic ground water}

All samples are prepared with ultra-pure water (Milli-Q system, $18.2 \mathrm{M} \Omega / \mathrm{cm}$ resistivity) and chemicals of reagent grade. The source of silicon was a standard solution of $\mathrm{Si}$ in $\mathrm{H}_{2} \mathrm{O}(1000$ mg/L, Spex Certiprep). The Wyoming MX-80 bentonite from American Colloid Co. is used as starting material for all experiments without any pretreatment. The MX-80 contains approximately $82 \%$ montmorillonite with the structural formula: $\mathrm{Na}_{0.30}\left(\mathrm{Al}_{1.55} \mathrm{Fe}_{0.21} \mathrm{Mg}_{0.24}\right)\left(\mathrm{Si}_{3.96} \mathrm{Al}_{0.04}\right) \mathrm{O}_{10}(\mathrm{OH})_{2}, \mathrm{M}_{\mathrm{w}}=372.6 \mathrm{~g} / \mathrm{mol}$ (Karnland et al., 2006) and has a cation exchange capacity (CEC) of approximately $0.75 \mathrm{meq} / \mathrm{g}$ (measured according to (Meier and Kahr, 1999)).

The fulvic acid (FA-573) used as organic matter in this study was extracted from a natural ground water (Gohy573) originating from the Gorleben site, Germany (Wolf et al., 2004) and subsequently purified and characterized. A detailed description can be found in (Wolf et al., 2004). The elemental composition of the FA used in this work is as follows (Wolf et al., 2004): C: $(54.1 \pm 0.1) \%, \mathrm{H}:(4.23 \pm 0.08) \%, \mathrm{O}:(38.94 \pm 0.04) \%, \mathrm{~N}:(1.38 \pm 0.02) \%$ and $\mathrm{S}:$ $(1.32 \pm 0.01) \%$. The proton exchange capacity is $6.82 \pm 0.04 \mathrm{meq} / \mathrm{g}$. In this study, a small amount of FA is weighted, dispersed in $\mathrm{NaOH}$ and diluted in the corresponding initial clay stock dispersions as described below. The dissolved organic carbon content is measured with a TOC analyser (TOC-5000, Shimadzu).

A synthetic carbonated ground water $(\mathrm{SGW})$ is prepared in order to simulate a glacial melt water of low ionic strength. In the present case, we tend to the composition of the granitic groundwater coming from the Grimsel Test Site (Geckeis et al., 2004; Möri et al., 2003). This is done by mixing the requested amounts of the different salts $\left(\mathrm{NaOH}, \mathrm{NaCl}, \mathrm{CaCl}_{2}, \mathrm{MgCl}_{2}\right.$, $\mathrm{NaF}, \mathrm{Na}_{2} \mathrm{SO}_{4}$ and $\mathrm{NaHCO}_{3}$ ) and an aliquot of the Si standard solution in ultra-pure water. The final composition of the SGW is the following: $\mathrm{Na}^{+}(28.4 \mathrm{mg} / \mathrm{L}, 1.2 \mathrm{mM}), \mathrm{Ca}^{2+}(1.49 \mathrm{mg} / \mathrm{L}$, $0.05 \mathrm{mM}), \mathrm{F}^{-}(2.8 \mathrm{mg} / \mathrm{L}, 0.1 \mathrm{mM}), \mathrm{Cl}^{-}(2.64 \mathrm{mg} / \mathrm{L}, 0.074 \mathrm{mM}), \mathrm{SO}_{4}{ }^{2-}(4.13 \mathrm{mg} / \mathrm{L}, 0.04 \mathrm{mM})$, 
$\mathrm{Si}(0.014 \mathrm{mg} / \mathrm{L}, 0.5 \mu \mathrm{M})$ and $\mathrm{HCO}_{3}{ }^{-}(84 \mathrm{mg} / \mathrm{L}, 1.4 \mathrm{mM})$. The ionic strength is below $2 \cdot 10^{-3} \mathrm{M}$ and the $\mathrm{pH}$ is $8.4 \pm 0.1$.

\subsection{Fractionation by sequential and direct (ultra-)centrifugation}

$50 \mathrm{~g}$ of unpurified MX-80 bentonite is added to $5 \mathrm{~L} \mathrm{SGW} \mathrm{(10} \mathrm{g} \mathrm{clay/L).} \mathrm{The} \mathrm{dispersion} \mathrm{is}$ regularly stirred during one day and then let to settle during three days in order to remove the larger clay fractions and accessory mineral phases. After sedimentation the top $4 \mathrm{~L}$ are isolated. It constitutes the colloidal dispersion S0. The residual solid phase (named R0) is stored for further studies (Figure S1 in the supporting information file 1 (SIF-1)). Sequential centrifugation (Thermo Scientific Centrifuge 2.0, with $50 \mathrm{~mL}$ PE centrifugation tubes, VWR, Germany) or ultra-centrifugation (Beckmann Ultracentrifuge, XL90, with 100 mL Quick-seal centrifuge tubes, Beckmann) is then performed at increasing speeds and times to obtain various clay colloidal dispersions, starting from the supernatant S0 similarly to the protocol presented in (Perret et al., 1994). The resulting supernatant after the first centrifugation step corresponds to the colloidal dispersion $\mathrm{S} 1$ and the corresponding solid residual, R1. Thereafter, the sequential centrifugation is repeated three times, where the last centrifugation step is an ultra-centrifugation, leading to the supernatant S3.5. A schematic diagram for the fractionation protocol is presented in the supporting information file 1, SIF-1, Figure S2. The corresponding centrifugation times and speeds are summarized in Table 1. Higher centrifugation speeds (up to $235000 \mathrm{~g}$ ) and filtrations (see SIF-2) are tested but result in removing a too large part of the clay particles. Consequently, only the fractions S0 to S3.5 are used in the present work.

In addition to the sequential centrifugation, and for comparison, two supernatants (noted with the prefix UC and UC, FA) are collected directly from the supernatant S0 after only one ultracentrifugation step, using the same speed and time as the ones used to obtain the dispersion 
S3.5. For that purpose, an initial supernatant S0 is collected after 1 day stirring and 3 days sedimentation as described above, in presence (UC, FA) or absence (UC) of $11.8 \mathrm{mg} / \mathrm{L}$ FA.

Finally, the truly dissolved concentrations of $\mathrm{Si}, \mathrm{Al}, \mathrm{Ca}, \mathrm{Mg}$ and $\mathrm{Fe}$ in equilibrium with clay minerals are those determined after the strongest centrifugation step (1h at $235000 \mathrm{~g}$, SIF-2). To determine the amount of each element in the clay particles, the truly dissolved concentration is subtracted from the total concentration measured in the dispersion.

Table 1: Conditions for fractionation of the clay dispersions, and clay aggregate sizes expected in the residuals ( $(\mathrm{Ri})$ and in the supernatants $(\mathrm{Si})$.

\begin{tabular}{|c|c|c|c|}
\hline Dispersion & $\begin{array}{l}\text { Conditions of separation } \\
\text { (C: centrifugation; } \\
\text { UC: ultracentrifugation) }\end{array}$ & $\begin{array}{l}\text { Size expected in the } i^{\text {th }} \\
\text { residual clay fraction (Ri) } \\
\text { in } n m\end{array}$ & $\begin{array}{l}\text { Size expected in the } i^{\text {th }} \\
\text { supernatant }(\mathrm{Si}) \text { in } \mathrm{nm}\end{array}$ \\
\hline S0 & 3 days sedimentation & $1000 \leq \mathrm{R} 0$ & $0 \leq \mathrm{S} 0 \leq 1000$ \\
\hline S1 & $\mathrm{C}: 30 \mathrm{~min}(\mathrm{~S} 0)$ at $313 \mathrm{~g}$ & $450 \leq \mathrm{R} 1 \leq 1000$ & $0 \leq \mathrm{S} 1 \leq 450$ \\
\hline S2 & $\mathrm{C}: 1 \mathrm{~h}(\mathrm{~S} 1)$ at $700 \mathrm{~g}$ & $200 \leq \mathrm{R} 2 \leq 450$ & $0 \leq \mathrm{S} 2 \leq 200$ \\
\hline S3 & $\mathrm{C}: 4 \mathrm{~h}(\mathrm{~S} 2)$ at $1200 \mathrm{~g}$ & $70 \leq \mathrm{R} 3 \leq 200$ & $0 \leq \mathrm{S} 3 \leq 70$ \\
\hline S3.5 & UC: $30 \mathrm{~min}(\mathrm{~S} 3)$ at $26000 \mathrm{~g}$ & $50 \leq \mathrm{R} 3.5 \leq 70$ & $0 \leq \mathrm{S} 3.5 \leq 50$ \\
\hline $\mathrm{S3.5} 5^{\mathrm{UC}}$ & $\mathrm{UC}: 30 \mathrm{~min}(\mathrm{~S} 0)$ at $26000 \mathrm{~g}^{\mathrm{a}}$ & $50 \leq \mathrm{R} 3.5^{\mathrm{UC}}$ & $0 \leq \mathrm{S} 3.5^{\mathrm{CC}} \leq 50$ \\
\hline $\mathrm{S3.5}^{\mathrm{UC}, \mathrm{FA}}$ & UC: $30 \min (\mathrm{S} 0)$ at $26000 \mathrm{~g}^{\mathrm{a}}$ & $50 \leq \mathrm{R} 3.5^{\mathrm{UC}, \mathrm{FA}}$ & $0 \leq \mathrm{S} 3.5^{\mathrm{UC}, \mathrm{FA}} \leq 50$ \\
\hline
\end{tabular}
stable at $9.4 \pm 0.2$. All the collected supernatants and solid residues are stored at $+4{ }^{\circ} \mathrm{C}$ in darkness before characterization and use in stability studies. 


\subsubsection{Ion and clay particle concentrations determination}

191

192

193

194

195

The element compositions are determined in all dispersions over time by Ion Chromatography (IC, ICS-3000) and ICP-OES (Optima 2000 DV, PerkinElmer). The samples are acidified before the ICP-OES measurements in $2 \% \mathrm{HNO}_{3}$ (Merck, ultrapure) plus a drop of HF (Merck, suprapure, $48 \%$ ).

\subsubsection{Mineral phase composition}

Mineral phases composing the clay particle dispersions and the solid residues are determined by XRD. The aim is to detect possible differences in the composition between the different size fractions. XRD data are collected on residuals and supernatants prepared as oriented samples obtained by drying on sample holders (low background Si wafers). The residuals are prepared by dilution of the solid-gel like dispersions in ultra-pure water. The SGW alone is also analyzed as a reference to identify any phase that could precipitate in the supernatants or residuals upon drying. X-ray diffractograms for all samples (raw MX-80, the supernatants and the residues) are also collected after saturation with ethylene glycol (SIF-4). Powder diffractograms are recorded with a D8 Advance (Bruker) diffractometer $\left(\mathrm{Cu} \mathrm{K} \mathrm{K}_{\alpha}\right.$ radiation) equipped with an energy dispersive detector (Sol-X). The phases are identified with the DIFFRAC.EVA version 2.0 software (Bruker) by comparison with the JCPDS 2 database.

\subsubsection{Content of organic matter}

The total amount of organic carbon in the dispersions prepared in presence of FA is measured with a TOC analyser (TOC-5000, Shimadzu). A change in the FA concentration is obtained after ultra-centrifugation (final $[\mathrm{FA}]=8.3 \mathrm{mg} / \mathrm{L}$ compared to $11.8 \mathrm{mg} / \mathrm{L}$ initially). This result indicates that a third of the organic matter might be associated with the clay aggregates while most of the FA (two thirds) remains in the dispersion under the present experimental conditions, as expected for these small-sized molecules and at the present $\mathrm{pH}$. 


\subsubsection{Size distribution measurements}

215

The size distributions of montmorillonite aggregates in all dispersions are determined by Photon Correlation Spectroscopy (PCS, homodyne single beam ZetaPlus System equipped with a 50mW solid-state laser emitting at $632 \mathrm{~nm}$, Brookhaven Inc, USA) and Asymmetric Flow Field-Flow Fractionation system (AsFlFFF, HRFFF 10.000 AF4, Postnova Analytics, Landsberg, Germany) coupled to a UV-Vis. detector (LambdaMax LC Modell 481, Waters, Milford, USA) and an Inductively-Coupled Plasma-Mass Spectrometer (ICP-MS, X-Series2, Thermo Scientific, Germany).

AsFlFFF/UV-Vis./MALLS/ICP-MS has previously been used for characterization of natural or synthetic clays colloids (Bouby et al., 2012; Bouby et al., 2011; Bouby et al., 2004; Finck et al., 2012; Plaschke et al., 2001). In this study, the clay dispersions obtained after fractionation $(\mathrm{Si})_{\mathrm{i}=0-3.5}$ are diluted to $\sim 20 \mathrm{mg} / \mathrm{L}$ clay particles in SGW before injection into the system. Details on the equipment, the fractionation conditions and the calibration are given in the supporting information file (SIF-3).

For the PCS measurements, the clay dispersions are diluted to $10 \mathrm{mg} / \mathrm{L}$ in a disposable plastic cuvette and measured over 5 runs consisting of 10 measurements of $15 \mathrm{~s}$ each, i.e. 50 measurements, for determination of mean hydrodynamic diameters.

\subsection{Clay particle stability studies}

Stability studies are performed using PCS-measurements according to the experimental protocol described in (Behrens et al., 2000; Czigány et al., 2005; Holthoff et al., 1996; Kretzschmar et al., 1998). The particle stability ratios (W) are calculated from the initial 
agglomeration rates. The stability ratio is defined as the ratio between the fast agglomeration rate to the measured agglomeration rate in the present sample:

$$
W=\frac{\left[\left(\frac{d r_{h}}{d t}\right)_{t \rightarrow 0} / C\right]^{(f)}}{\left[\left(\frac{d r_{h}}{d t}\right)_{t \rightarrow 0} / C\right]}
$$

where $r_{h}$ is the hydrodynamic radius (nm), $t$ the time (s) and $C$ the particle concentration (mg/L), the suffix $f$ represents the fast agglomeration rate. Equation 1 is derived from the following Equations 2 and 3:

$$
\begin{gathered}
\left(\frac{d r_{h}}{d t}\right)_{t \rightarrow 0}=\beta k C \\
W=\frac{k^{(f)}}{k}=\frac{1}{\alpha}
\end{gathered}
$$

where $\beta$ is an optical factor (depending on the scattering angle, the wavelength of the light and the particle radius), $k$ is the agglomeration rate and $\alpha$ is the particle-particle attachment efficiency and so-called the sticking probability. Consequently, W approaches 1 when the particles are unstable under the chemical conditions tested, while for stable dispersions, W tends to go to infinity (set arbitrarily to $10^{1}-10^{2}$ values in our experiments to fit into the graphs).

In this study, $\mathrm{W}$ is determined at $\mathrm{pH} 7$, while the ionic strength was varied between 0.01 and 3 $\mathrm{M}$ by using the electrolytes $\mathrm{NaCl}, \mathrm{CaCl}_{2}$ or $\mathrm{MgCl}_{2}$. In addition, experiments in presence or absence of FA are performed, since FA is known to stabilize montmorillonite particles (Furukawa and Watkins, 2012). The clay particle concentration is fixed to $10 \mathrm{mg} / \mathrm{L}$ by prior dilution throughout all measurements, and all the supernatants listed in Table 1 are studied. The initial intensity-weighted hydrodynamic mean diameter is measured first during $45 \mathrm{~s}$ before addition of the electrolyte to the dispersion. Thereafter, the evolution of the particle hydrodynamic diameter is monitored, after affecting the dispersion by simultaneous addition 
of concentrated electrolyte aliquots $\left(\mathrm{NaCl}, \mathrm{CaCl}_{2}\right.$ or $\left.\mathrm{MgCl}_{2}\right)$ and $\mathrm{NaOH}$ to reach the desired chemical conditions. All samples are measured up to between 20 and 40 min after addition of the electrolyte, with measurements of $15 \mathrm{~s}$ each. To investigate the effects of addition of FA, a final concentration of $10.2 \mathrm{mg} \mathrm{FA} / \mathrm{L}$ is added to all clay dispersions. Thereafter, $0.1 \mathrm{M} \mathrm{CaCl}_{2}$ is added to the dispersions and the results are compared to measurements in absence of FA. As the $\mathrm{pH}$ cannot be monitored at the same time in the cuvette used for the PCS measurement, it is measured in parallel in a second cuvette with a dispersion of identical composition.

The initial agglomeration rate is determined by fitting a second-order polynomial to the experimental data, using the first 15-35 data points of each set of data. The initial agglomeration rates are then compared and normalized to the fastest initial agglomeration rate (determined for each electrolyte at $3 \mathrm{M}$ IS) for each colloidal fraction to obtain the corresponding $\mathrm{W}$ value.

\section{Results and Discussion}

\subsection{Characterization of the clay colloidal dispersions}

\subsubsection{Ion and colloid concentrations}

The concentrations of all analyzed elements are presented in Table 2, where the mean values obtained from several measurements are given. The clay colloid concentrations ([Coll.]) are calculated from Al-concentrations according to the theoretical structural formula (Karnland et al., 2006). The molar ratios of the different elements are calculated from the ICP-OES- and IC-results and may be compared to the theoretical values based on the assumed stoichiometry.

Table 2: Element and colloid concentrations in the clay colloidal dispersions measured by ICP-OES and IC and colloidal fraction distributions calculated from the mean concentration of four main and minor clay constituents ( $\mathrm{Si}, \mathrm{Al}, \mathrm{Mg}$, and $\mathrm{Fe}$ ). The recovered amount of colloids in the dispersions is presented as 
percentage compared to the initial colloidal concentration in SO. *: This corresponds to the amount of stable colloids in the dispersions after letting settle the dispersions during 2 months without any shaking.

284 The elemental mole ratios are corrected by the free aqueous concentrations determined after the strongest ultracentrifugation, which are $7.5 \cdot 10^{-5} \mathrm{M} \mathrm{Si}, 4.1 \cdot 10^{-6} \mathrm{M} \mathrm{Mg}, 7.2 \cdot 10^{-7} \mathrm{M} \mathrm{Fe}, 3.7 \cdot 10^{-6} \mathrm{M} \mathrm{Al}$ and $8.5 \cdot 10^{-6} \mathrm{M} \mathrm{Ca}$.

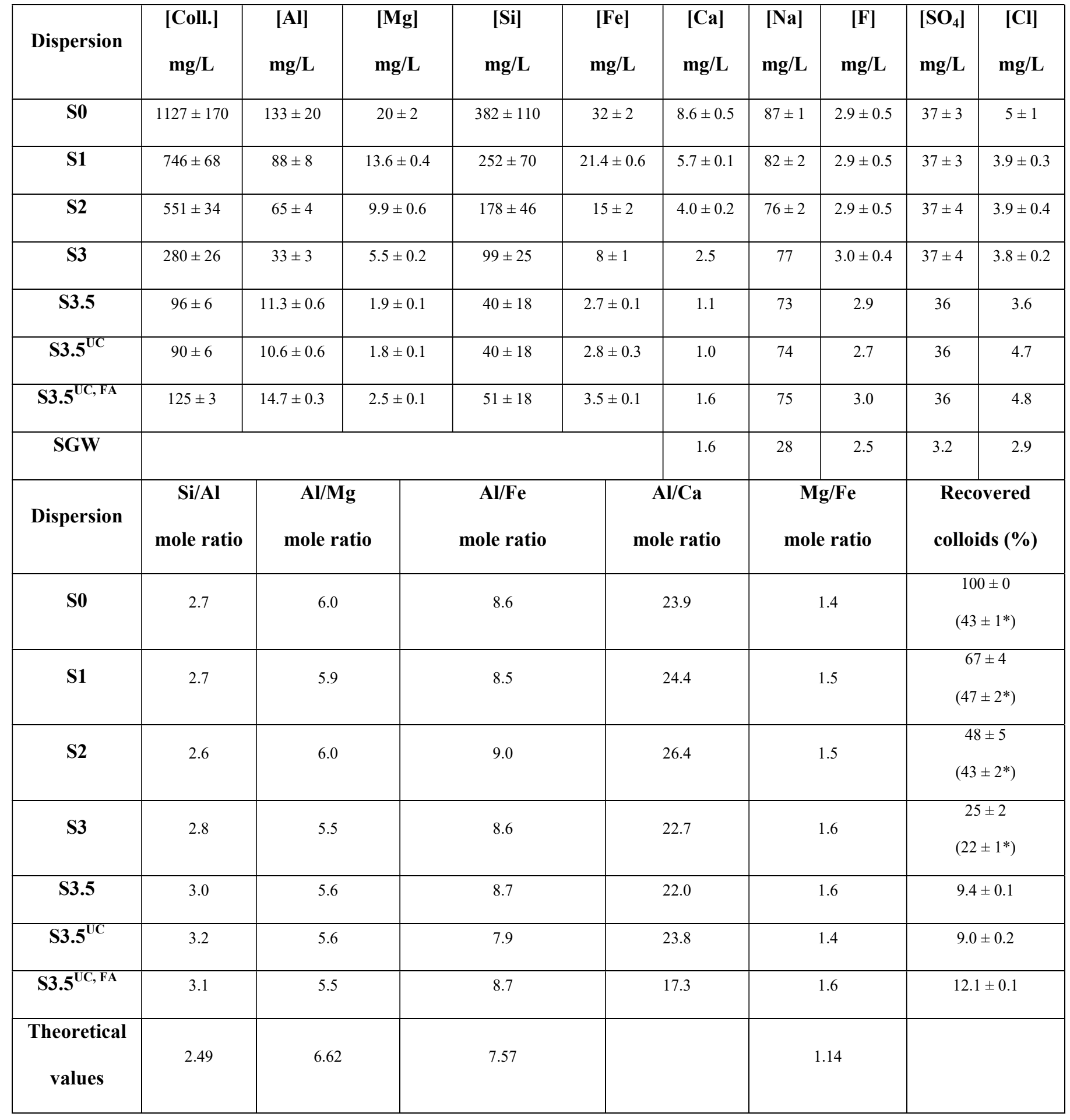


As expected, the montmorillonite colloid concentration decreases with the number of sequential centrifugation steps, for increasing centrifugation speed and time (Table 2). There is no doubt that the particles consist of montmorillonite in all dispersions as the $\mathrm{Si} / \mathrm{Al}, \mathrm{Al} / \mathrm{Mg}$, $\mathrm{Al} / \mathrm{Fe}$ and $\mathrm{Mg} / \mathrm{Fe}$ mole ratios are in fair agreement with those obtained from the theoretical structural formula of montmorillonite (Table 2). Molar element ratios in the clay fraction are corrected for the free aqueous concentration of dissolved elements in the dispersions. These free aqueous concentrations are obtained from the supernatant of a sample centrifuged at 235 $000 \mathrm{~g}$ where all clay mineral particles are assumed to be removed (SIF-2). The calcium concentrations in the dispersions decrease with increasing numbers of centrifugation steps similar to the decrease of colloid concentrations (Table 2) suggesting its association to the clay aggregates, possibly due to ion exchange binding at the permanently charged basal plane. Even though calcium does not appear in the theoretical formula, it is known that unpurified MX80 bentonite contains calcium based accessory minerals, like calcite (Bradbury and Baeyens, 2002; Karnland et al., 2006; Vuorinen and Snellman, 1998).

In addition, the results show a direct release of several elements from the unpurified bentonite to the SGW, which is here the background electrolyte (Table 2). A drastic increase of sodium and sulfate and, to a lower extend, fluoride and chloride is observed as already reported in the literature (Bradbury and Baeyens, 2002; Vuorinen and Snellman, 1998). This can be explained, altogether, by the presence of $\mathrm{NaCl}(1.35 \mathrm{mmol} / \mathrm{kg})$, fluorite $\left(\mathrm{CaF}_{2}\right)$, gypsum $\left(\mathrm{CaSO}_{4}\right)$ and celestite $\left(\mathrm{SrSO}_{4}\right)$ in the unpurified MX80 (Bradbury and Baeyens, 2002; Vuorinen and Snellman, 1998). The dissolution of $\mathrm{NaCl}$ from the unpurified starting material cannot explain the large increase of sodium concentration in the supernatants. In addition, no increase in $\mathrm{Ca}$ concentration is observed (the concentration of $\mathrm{Sr}$ is not measured). Cation exchange reactions, where divalent cations $(\mathrm{Ca} / \mathrm{Sr})$ are favored over monovalent ones $(\mathrm{Na})$, may explain why the Na release is enhanced and no variation in Ca concentration is observed 
(Gaucher et al., 2009). Another process involving dissolution of pyrite, which is found in the

313 XRD analysis (Figure 1), can explain the release of sulfate. However, this should be accompanied by a drop of $\mathrm{pH}$. Thus, it is not considered as the most important process.

\subsubsection{Colloidal distribution in the montmorillonite fractions and long-term stability of} the dispersions

The mean clay colloidal concentrations after each centrifugation are calculated from the concentrations obtained for the four main and minor montmorillonite constituents ( $\mathrm{Si}, \mathrm{Al}, \mathrm{Mg}$, and $\mathrm{Fe}$ ). They are compared to the initial concentration of colloids, which allows determining the colloidal recoveries, Table 2.

From the total amount of colloids initially present in S0, approx. $9 \%$ remain in the dispersion $g$ ultra-centrifugation. The similarity of the results obtained after one direct ultracentrifugation step $\left(\mathrm{S} 3.5^{\mathrm{UC}}, 9.0 \pm 0.2 \%\right)$ is noticeable. A slightly higher recovery of clay colloids is obtained in presence of fulvic acids (S3.5 $\mathrm{UC}$,FA, $12.1 \pm 0.1 \%$ ), which indicates that the negatively charged FA may have stabilized a part of the montmorillonite colloids initially present in dispersion (Furukawa and Watkins, 2012; Kretzschmar et al., 1998).

To determine the long-term stability of the dispersions, the same analyses were performed 2 months later, without any shaking during that time or prior to the sampling. It is found that not all dispersions are stable over time. This is particularly true for the dispersions S0 and S1 as indicated by the percentage of colloids recovered after 2 months (Table 2, marked with *) showing that $57 \%$ and $26 \%$ of the clay colloids, respectively, have sedimented during this time period. This indicates that these dispersions contain various sizes fractions, from large to smaller clay aggregates, as expected from the sequential separation protocol. 
The as-received material, MX-80, consists mainly of montmorillonite, as indicated by the corresponding X-ray diffractogram (Figure 1). Accessory minerals are present in the unpurified bentonite such as quartz, cristobalite and mica, as well as trace amounts of albite, feldspar and pyrite. No attempt was made to quantify their content. This bentonite composition agrees well with reported data (Hu et al., 2009).

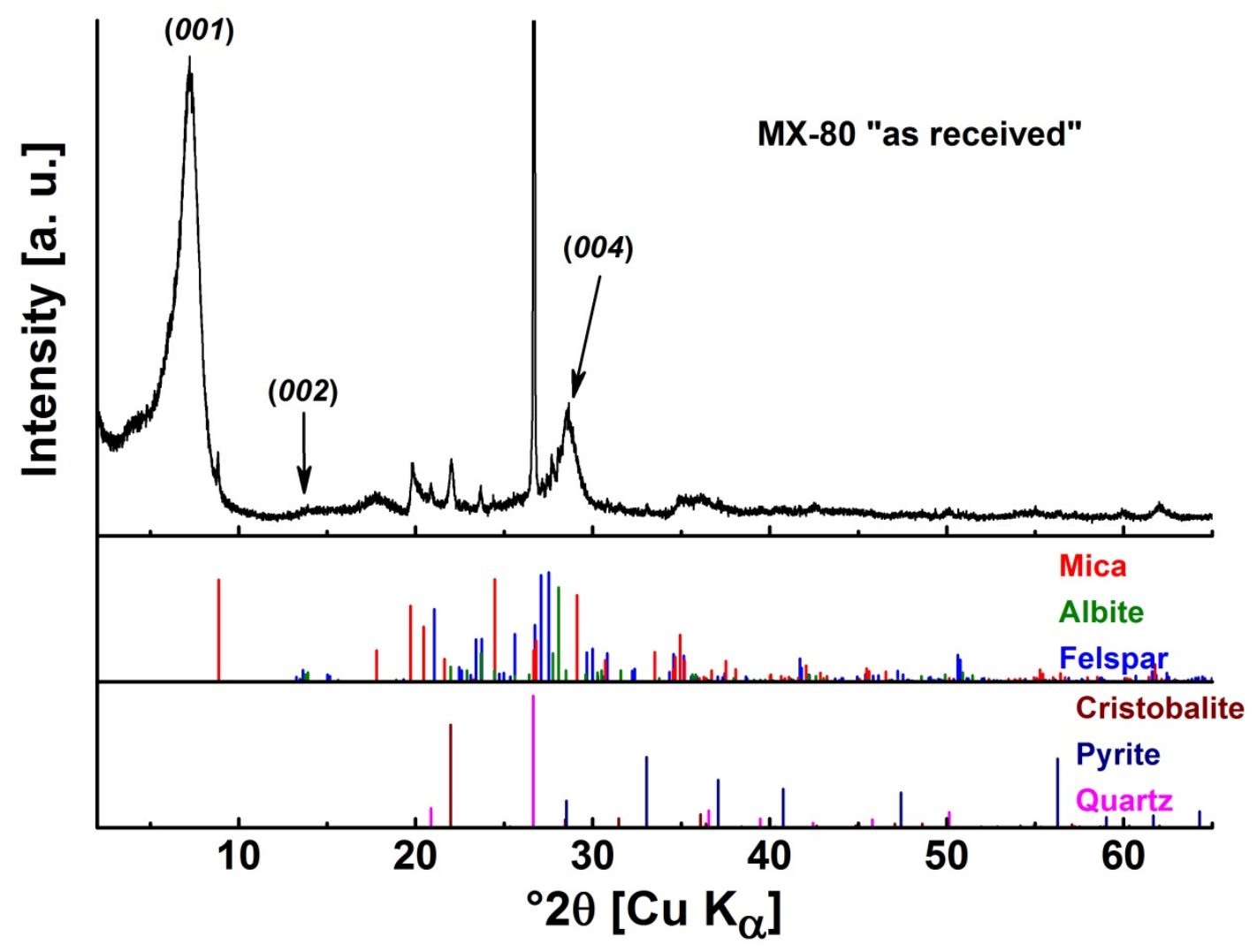

Figure 1: X-ray diffractogram of the as-received MX-80 and identification of the accessory minerals by comparison with database. Montmorillonite $00 l$ planes are indicated in brackets.

The supernatants and residuals are all analyzed after each fractionation step (Figure 2). The solid material in R0 has identical mineralogical composition as the raw material. Obviously, the accessory phases settled down during the first fractionation step resulting in that cristobalite is detected only in the first sample and that quartz can be detected only in S0 and R1. All samples, both residuals and supernatants, exhibit intense reflections at $12.2-14.6 \AA$ $\left(\begin{array}{ll}\left.7.2-6.0^{\circ} 2 \theta\right) \\ 2\end{array}\right)$ and $\sim 3.14 \AA\left(28.6^{\circ} 2 \theta\right)$ corresponding to 001 and 004 reflections of 
montmorillonite. The 001 reflection or basal spacing (i.e. $\mathrm{d}(001)$ ), which corresponds to the $c$ dimension of the elemental unit cell, is dependent on the hydration state (Ferrage et al., 2005; Meunier, 2005). In this study, all supernatants and residuals have a basal spacing corresponding to the presence of one $(12.2 \AA)$ and two water molecules $(14.6 \AA)$ in the interlayer. In R1 and R2, the clay is obviously heterogeneous in the hydration state as both states may be present as shown by the broad 001 reflection. The clay interlayer hydration state depends on the layer charge and the ambient relative humidity, not on the fractionation procedure. All samples also exhibit less intense $00 l$ reflections typical of clay minerals, such as 002 and 006 . Finally, all residues have a similar mineralogical composition except the quartz detected in trace amounts in R1. Likewise, all suspended particles in supernatants have a similar mineralogical composition, except $\mathrm{S} 0, \mathrm{~S} 1$ and $\mathrm{S} 2$ that contain cristobalite and $\mathrm{S} 0$ that contains additionally trace amount of quartz. Finally, only halite $(\mathrm{NaCl})$ and $\mathrm{Na}_{2} \mathrm{CO}_{3}$ could be detected in SGW meaning that these phases crystallized upon drying. Halite could be detected in some supernatants. None of these phases $\left(\mathrm{NaCl}\right.$ or $\left.\mathrm{Na}_{2} \mathrm{CO}_{3}\right)$ could be detected in the residues.

All supernatants and residuals exhibit similar basal spacing after saturation with ethylene glycol (SIF-4). The expansion to $17.0 \pm 0.2 \AA$ for $\mathrm{d}(001)$ is typical of smectite swelling, and thus consistent with montmorillonite being the main component of MX-80. 

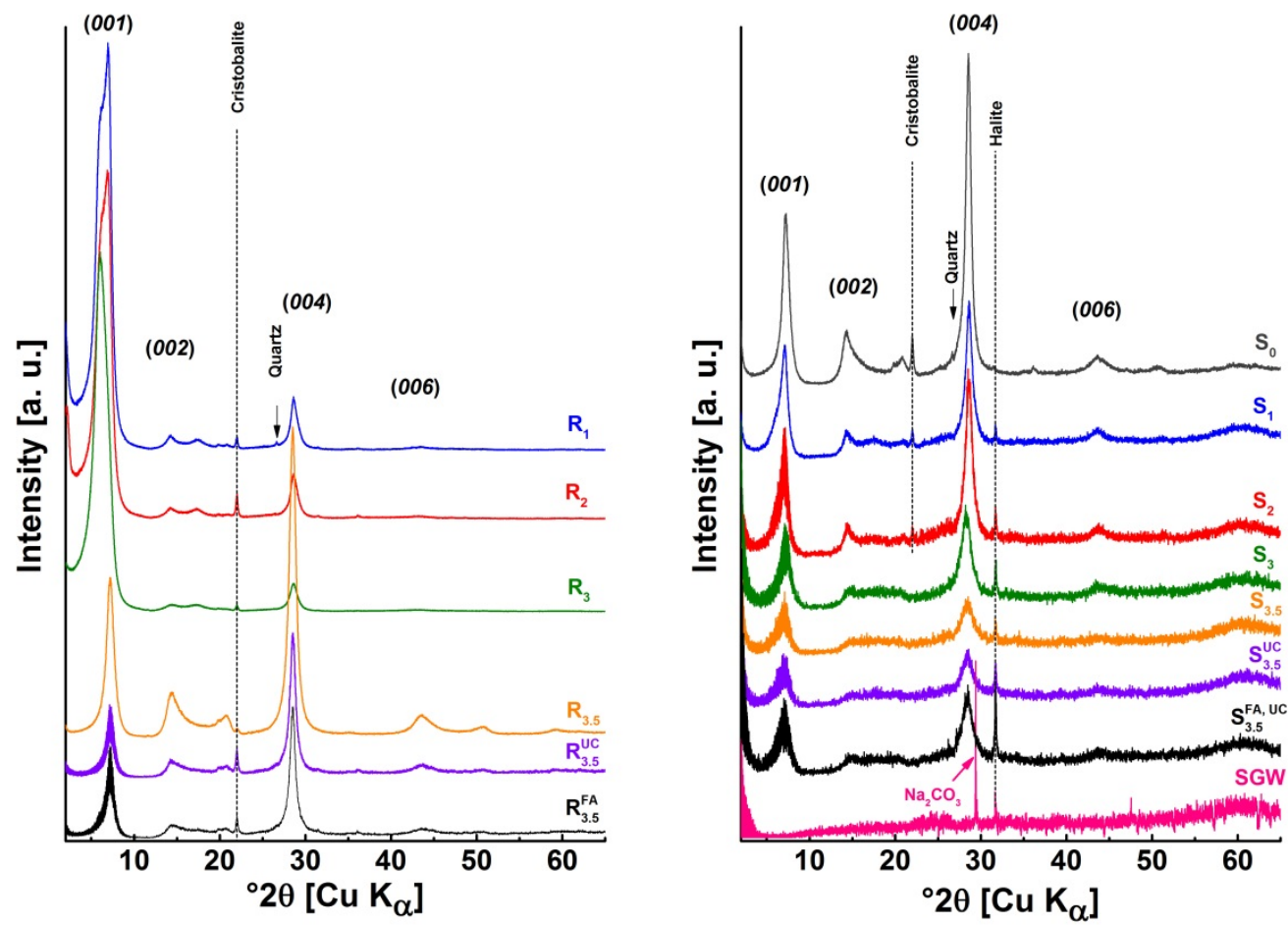

Figure 2: X-ray diffractograms for all residuals (left) and supernatants (right) obtained by fractionation. One can see the similarities between the residuals and supernatants, which implies a similar structure of the montmorillonite in the different samples. In addition, a decrease in accessory minerals with the number of centrifugation steps is seen. The montmorillonite $00 l$ planes are indicated in brackets.

\subsubsection{Clay aggregate size distribution measurements}

Since aluminium is one of the main components of montmorillonite, the Al-data obtained from the AsFlFFF/ICP-MS-measurements are used as a clay indicator. All Al-ICP-MS data

377 are presented in Figure 3 after transformation of fractograms in mass versus size by using 1)

378 the mass calibration method (left side, Figure 3a) as developed before in previous studies

379 (Bouby et al., 2008) and 2) the size calibration (right side, figure 3b), according to (Schimpf et al., 2000). 

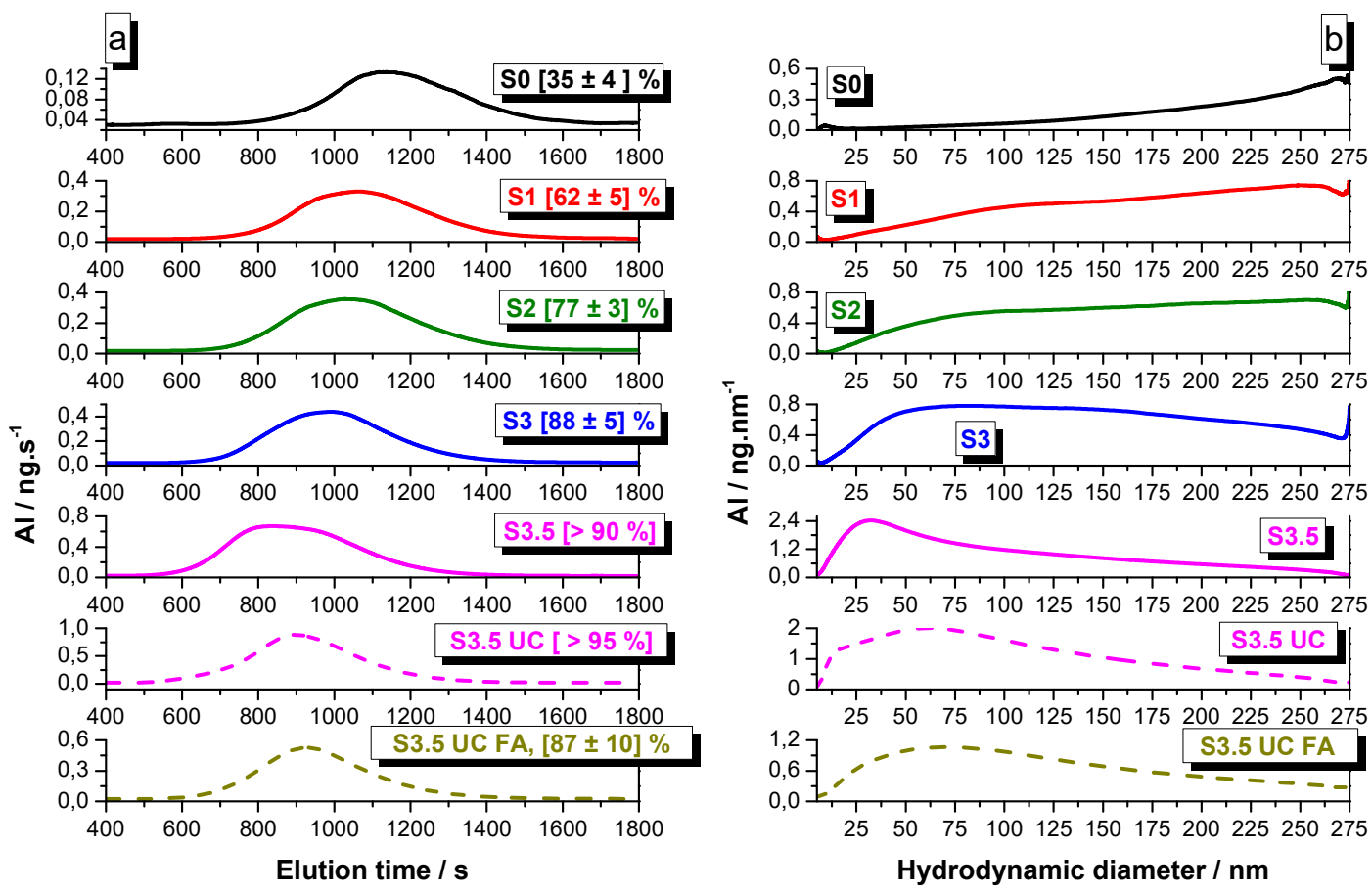

Figure 3: Al-ICP-MS fractograms obtained after injection $(100 \mu \mathrm{L})$ of the different clay dispersions, all diluted to $20 \mathrm{mg} / \mathrm{L}$ clay prior to injection. Left: fractograms transformed using the calibration in mass concentration as a function of elution time (Bouby et al., 2008). Right: fractograms further transformed by using the calibrations to size (Schimpf et al., 2000). The percentage in bracket indicates the colloid recovery in the measurements. These are all smoothed data and a mean result of two measurements.

At a first look, a broad size distribution is obtained for each dispersion, ranging from 10 up to $275 \mathrm{~nm}$. Some shoulders are clearly visible in the fractograms, indicating the presence of different size fractions in the dispersions. A separation into different well-resolved size fractions is not achieved due to the conditions selected for the AsFlFFF measurements (see SIF-3). Nevertheless, the fractograms show clearly that the mean size of the aggregates in the dispersions is decreasing with the number of fractionation steps. This is clearly evidenced by the significant variation of the fractogram maxima and the mean sizes of the different colloidal dispersions (Figure 3 and Table 3). 
Table 3: Peak maxima and mean aggregate sizes of the dispersions obtained from AsFIFFF-/ICP-MS measurements with the corresponding mean intensity (I)- and volume (V)-weighted sizes determined from PCS analysis from the multimodal size distribution (MSD). The colloid recovery in the AsFIFFFmeasurements increases with decreasing sizes. $d_{T} / d_{S}$ : equivalent spherical diameter (ESD) ratios, where $d_{T}$ is the ESD for a translating disc-shaped particle determined by PCS (mean volume-weighted value, PCS $_{\mathrm{v}}$ ) and $d_{\mathrm{s}}$ is the equivalent Stokes' spherical diameter for a sedimenting particle determined by AsFIFFF (mean value); $\rho$ : calculated axial ratio, see section 3.1.4.2 for details.

\begin{tabular}{|c|c|c|c|c|c|c|c|c|c|}
\hline & & $\begin{array}{l}\text { le (peak m } \\
\qquad(\mathrm{nm})\end{array}$ & & PCS & & Mean (nm) & & $\begin{array}{r}\text { From }( \\
\text { and } P \\
19\end{array}$ & ings \\
\hline Sample & ASFIFFF & $\begin{array}{l}\text { Half- } \\
\text { width }\end{array}$ & $\begin{array}{c}\text { Recovery } \\
\text { (\%) }\end{array}$ & $\begin{array}{c}\text { Average } \\
\text { count } \\
\text { rate } \\
\text { (kcps) }\end{array}$ & $\begin{array}{c}\mathbf{P C S}_{\mathrm{I}} \\
\text { (MSD) }\end{array}$ & $\begin{array}{c}\mathbf{P C S}_{\mathbf{V}} \\
\left(\mathbf{d}_{\mathbf{T}}\right) \\
(\mathbf{M S D})\end{array}$ & $\begin{array}{c}\text { AsFIFFF } \\
\left(d_{s}\right)\end{array}$ & $\mathbf{d}_{\mathrm{T}} / \mathbf{d}_{\mathrm{S}}$ & $\rho$ \\
\hline So & $264 \pm 9$ & $64 \pm 47$ & $35 \pm 4$ & $118 \pm 7$ & $1452 \pm 632$ & $962 \pm 225$ & $229 \pm 5$ & 4.20 & 66.3 \\
\hline S1 & $243 \pm 28$ & $183 \pm 24$ & $62 \pm 5$ & $87 \pm 2$ & $513 \pm 60$ & $610 \pm 57$ & $198 \pm 13$ & 3.07 & 34.6 \\
\hline S2 & $255 \pm 21$ & $217 \pm 4$ & $77 \pm 3$ & $53 \pm 1$ & $404 \pm 95$ & $337 \pm 29$ & $189 \pm 7$ & 1.78 & 10.3 \\
\hline S3 & $80 \pm 5$ & $232 \pm 18$ & $88 \pm 5$ & $37 \pm 1$ & $248 \pm 28$ & $186 \pm 64$ & $151 \pm 14$ & 1.23 & 3.7 \\
\hline S3.5 & $33 \pm 3$ & $83 \pm 15$ & $>90$ & $20 \pm 1$ & $181 \pm 28$ & $172 \pm 49$ & $84 \pm 8$ & 2.06 & 14.4 \\
\hline S3.5.$^{\mathrm{UC}}$ & $61 \pm 6$ & $142 \pm 12$ & $>95$ & $25 \pm 1$ & $180 \pm 39$ & $167 \pm 50$ & $95 \pm 13$ & 1.76 & 10.0 \\
\hline S3.5 . $^{\mathrm{UC}, \mathrm{FA}}$ & $70 \pm 6$ & $167 \pm 1$ & $87 \pm 10$ & $29 \pm 1$ & $185 \pm 47$ & $143 \pm 43$ & $124 \pm 24$ & 1.16 & 3.0 \\
\hline
\end{tabular}

The half-width values decrease only slightly for the dispersions S0 to S3.5 indicating that a rather broad character of the size distributions remains. In addition, it should be noted that the mean clay aggregate sizes obtained in the dispersions is higher than expected (Table 1), especially for the dispersions where the smallest size is expected, i.e. in S3 and all S3.5 dispersions. This may be interpreted as an incomplete sedimentation during the centrifugation 
due to the inaccurate assumption made considering a spherical shape of the particles in the Stokes' law calculation, since the particle shape is of high importance while included in Stokes' law (Kunkel, 1948).

The colloid recovery for each AsFIFFF-measurement (indicated in brackets in the legend in Figure $3 \mathrm{a}$ and in Table $3,4^{\text {th }}$ column) can also help to understand the results. One explanation for the low recoveries in S0 to S2 runs is the loss of particles in the AsFlFFF-channel due to an irreversible attachment of notably larger sized aggregates to the membrane during the fractionation process. The lower recovery of the Al-mass especially for the dispersions S0 and S1 indicates the presence of large aggregates attaching to the accumulation wall in the channel or moving too slowly to be detected under these conditions. This is in agreement with the slow sedimentation process observed in the unstirred dispersions S0 and S1 over time (Table 2). The recovery increases significantly with higher centrifugation forces, where higher recoveries are reached for the dispersions obtained after the ultra-centrifugation step (S3.5 and $\left.\mathrm{S} 3.5^{\mathrm{UC}}\right)$

\subsubsection{PCS}

To complement the AsFIFFF analysis, the dispersions are monitored by PCS after dilution to $10 \mathrm{mg} / \mathrm{L}$ clay. The results of the PCS analyses are presented in Table 3 . The table presents the average count rates (in kilo counts per second (kcps)) which clearly decrease for centrifugation steps with higher rotation rates, even though the colloid mass concentrations are the same. Since the scattered intensity is highly dependent on the particle size, this is in line with the size variations seen in the AsFlFFF-measurements (Table 3). The corresponding values for the mean diameters of the clay aggregates are given, both as intensity-weighted $\left(\mathrm{PCS}_{\mathrm{I}}\right)$ and as volume-weighted $\left(\mathrm{PCS}_{\mathrm{V}}\right)$ in Table 3 as obtained from the measurements by 
considering the multimodal size distribution using the Non-Negatively constrained Least Squares (NNLS) algorithm to fit the data (Bro and De Jong, 1997). The volume-weighted diameter values $\left(\mathrm{PCS}_{\mathrm{V}}\right)$ are those which can be compared directly with the AsFlFFF data. Looking into Table 3 (column 7 and 8), the results are comparable. The differences are explained by losses of large particles in the AsFlFFF channel (especially for samples S0 and S1) and by recalling that the PCS preferentially detect larger sized entities.

Nowadays, it is recognized that several techniques have to be used to combine the results from particle size measurements and draw a more realistic description of a natural or synthetic sample, containing particles of irregular shapes, especially clay nanoparticles (Beckett et al., 1997; Bowen, 2002; Bowen et al., 2002; Cadene et al., 2005; Gallego-Urrea et al., 2014; Gantenbein et al., 2011; Plaschke et al., 2001; Veghte and Freedman, 2014). More information can be obtained from the AsFlFFF and PCS data following the development of (Jennings and Parslow, 1988) extended by e.g. (Bowen et al., 2002), (Pabst and Berthold, 2007) and (Gantenbein et al., 2011). In brief, whatever equipment is used, the dimensions obtained are equivalent sphere diameters (ESD) i.e. the diameters of spheres that would behave the same as the particles in the sample, as a function of the method used. One should have in mind that the ESD describes a 3-dimensional object with only one number. Flow FFF provides a direct access to the Stokes' diameter $\mathrm{d}_{\mathrm{S}}$ (Schimpf et al., 2000). "Particles under the influence of Brownian agitation translate for all orientations and it is the random orientation translation that is analysed in the PCS method" (Jennings and Parslow, 1988). Accordingly, the PCS gives access to the equivalent diameter from frictional translatory diffusion data, $\mathrm{d}_{\mathrm{T}}$. Consequently, except for spherical particles, one cannot expect the derived ESD to be identical from the two techniques as different physical phenomena are the basis of the measurements. This is used presently as an advantage considering that no identical results reveal the non-sphericity of the particles to be analysed and can thus serve to measure it. We 
develop that possibility in the following discussion by comparing the ESD values $\left(\mathrm{d}_{\mathrm{S}}\right)$ obtained with the AsFIFFF and the ESD values $\left(\mathrm{d}_{\mathrm{T}}\right)$ obtained with the PCS, i.e. the volumeweighted ones from the MSD fitting.

According to Jennings (Jennings, 1993), a comparison between the ESD values from the $\operatorname{AsFlFFF}\left(d_{S}\right)$ and PCS $\left(d_{T}\right)$ gives access to the mean clay axial ratio $(\rho)$ for the aggregates in each dispersions defined as the aggregate surface diameter to thickness ratio for each dispersions. In previous works (Jennings, 1993; Jennings and Parslow, 1988), Jennings presents the mathematical expressions of the equivalent spherical diameter (ESD) according to the analytical method used for its determination which are functions of the axial ratio. The equations are given primarily for oblate and prolate spheroids with two limiting geometry cases considered: the rod and the disc (to which the clay aggregate geometry may be simplified). The ESD for a translating disc-shaped particle $\left(\mathrm{d}_{\mathrm{T}}\right)$ and the equivalent Stokes' diameter $\left(\mathrm{d}_{\mathrm{S}}\right)$ for a sedimenting particle are expressed in equation (4) and (5) as (Jennings and Parslow, 1988):

$$
\frac{d_{T}}{\delta}=\frac{\sqrt{\rho^{2}-1}}{\rho \cdot \arctan \left(\sqrt{\rho^{2}-1}\right)}
$$

$$
\frac{d_{S}}{\delta}=\sqrt{\frac{\arctan \left(\sqrt{\rho^{2}-1}\right)}{\sqrt{\rho^{2}-1}}}
$$

where $\rho=\delta / t$ is the axial ratio of the disc-shaped particle, with $\delta$ being the surface diameter of the disc-shaped particle and $t$ its thickness.

Consequently, for a given particle, the ratio of these two ESD expressions may be used inversely a posteriori to evaluate the axial or aspect ratio $(\rho)$ of the particle and thus to obtain the value of $\delta$ and $t$, if the clay aggregate is approximated by a disc of diameter $\delta$ and thickness $t$. In the present work, the ratio $\mathrm{d}_{\mathrm{T}} / \mathrm{d}_{\mathrm{S}}$ correspond to the ratio of the ESD determined 
by $\operatorname{AsFlFFF}\left(\mathrm{d}_{\mathrm{S}}\right)$ and PCS $\left(\mathrm{d}_{\mathrm{T}}\right)$ (volume-weighted mean value, $\mathrm{PCS}_{\mathrm{v}}$ ). The calculated $\mathrm{d}_{\mathrm{T}} / \mathrm{d}_{\mathrm{S}}$

480 from the experimental mean diameters are presented in Table 3. The theoretical curve $\mathrm{d}_{\mathrm{T}} / \mathrm{d}_{\mathrm{S}}=\mathrm{f}(\rho)$ obtained from Equation 4 and Equation 5 is plotted in Figure 4 and is used to deduce the axial ratio $(\rho)$ for each clay colloid dispersion reported in Table 3.

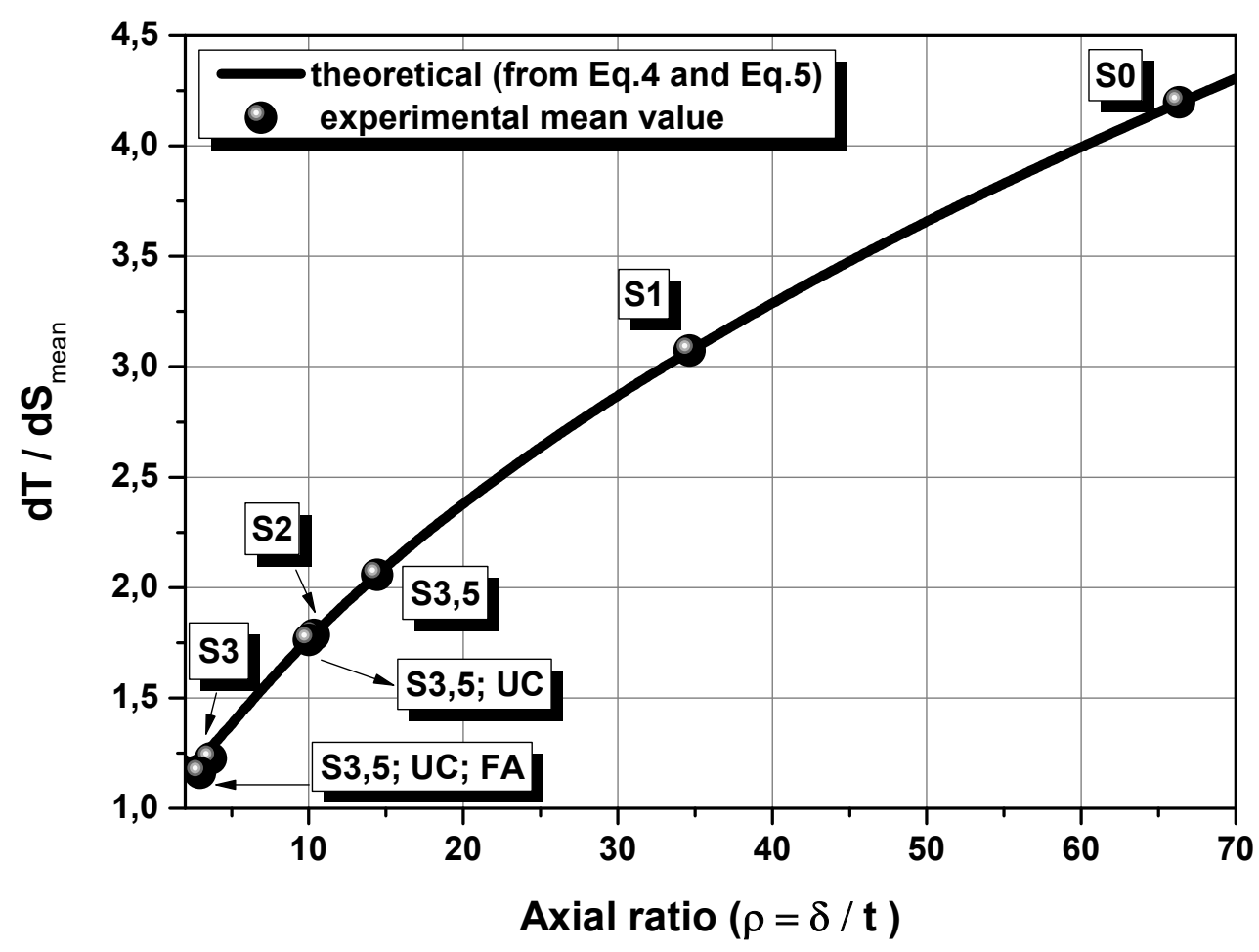

483

Figure 4: Theoretical $d_{T} / d_{\mathrm{S}}$-ratio values calculated as a function of the axial ratio (black line) using equations (4) and (5). The $\mathrm{d}_{\mathrm{T}} / \mathrm{d}_{\mathrm{S}}$-ratio values determined from the experimental mean PCS and AsFIFFF ESD data are reported for each dispersion. A posteriori, the corresponding axial ratio is obtained and presented in Table 3.

Obviously, $\rho>1$ for each dispersion as expected for clay aggregates having a disc-shaped geometry. Interestingly, the $\rho$-values are decreasing with increasing fractionation steps from $\sim 35$ (S1) down to $\sim 3.7$ (S3). (Note: due to the low AsF1FFF recovery, the $\rho$-value obtained for 491 S0 ( 66) is biased). 
Once $\rho$-values are known for each dispersion, one can back-calculate the corresponding mean surface diameter, $\delta$, and thickness, $t$, by using Equation 4 and Equation 5. The number of clay layers is calculated by taking $1.3 \mathrm{~nm}$ as the thickness of one single clay mineral layer (basal spacing) obtained by XRD results and according to (Meunier, 2005). The results are summarized in Table 4. According to literature, the clay aggregates dimensions reported in this work are plausible (Bergaya et al., 2006; Bouby et al., 2011; Hauser et al., 2002; Missana et al., 2003; Plaschke et al., 2001; Schramm and Kwak, 1982a, b; Sposito, 1992; Tournassat et al., 2011; Tournassat et al., 2003). The aspect ratio values determined agree with literature data (Ali and Bandyopadhyay, 2013; Cadene et al., 2005; Gélinas and Vidal, 2010; Plaschke et al., 2001; Tournassat et al., 2011; Tournassat et al., 2003; Weber et al., 2014; Veghte and Freedman, 2014). Pictures obtained from SEM analysis of the dispersions S0 to S3 are presented in the supporting file (see SIF-5). A raw evaluation of the AsFlFFF/MALLS data according to (Baalousha et al., 2005; Baalousha et al., 2006; Kammer et al., 2005) allows to compare the hydrodynamic $\left(R_{h}\right)$ versus gyration $\left(R_{g}\right)$ radius. The corresponding ratio $\left(R_{g} / R_{h}\right)$, called the shape factor, varies in the range [1.5-4] for the present measurements, and equals to 1 for a spherical particle. The shape factor increases as soon as the particles deviate from a spherical shape, indicating that the montmorillonite aggregates are non-spherical.

Table 4: Mean disc surface diameters $(\delta)$ and number of layers calculated from PCS and AsFIFFF mean equivalent sphere diameters (ESD) and the mathematical equations 4 and 5, according to (Jennings and Parslow, 1988) for the clay aggregates. The number of layers is calculated by taking $1.3 \mathrm{~nm}$ as the thickness, $t$, of one clay sheet, according to XRD results when considering one water layer.

\begin{tabular}{|c|c|c|c|c|c|c|}
\hline Sample & Axial ratio & PCS & AsFIFFF & $\delta$ & Number of \\
& $\rho=\delta / t$ & $\mathbf{d}_{\mathrm{T}} / \delta$ & $\mathbf{d}_{\mathbf{S}} / \delta$ & (disc $\mathbf{~} ;$ nm) & (disc thickness; nm) & 23 \\
\hline S0 & 66.3 & 0.643 & 0.226 & 1496 & 27 \\
\hline S1 & 34.6 & 0.648 & 0.325 & 940 & 48 \\
\hline
\end{tabular}




\begin{tabular}{|c|c|c|c|c|c|c|}
\hline $\mathbf{S 3}$ & 3.7 & 0.743 & 0.546 & 250 & 68 & 52 \\
\hline $\mathbf{S 3 . 5}$ & 14.4 & 0.664 & 0.303 & 258 & 18 & 14 \\
\hline $\mathbf{S 3 . 5}$ & 10.0 & 0.676 & 0.385 & 246 & 25 & 19 \\
\hline $\mathbf{S 3 . 5}$ & & & & & & \\
\hline
\end{tabular}

514 By plotting the oblate spheroid ESD as a function of the axial ratio (Jennings and Parslow, 515 1988), the ESD is found to always be smaller than the true dimension, $\delta$. This is true for both measurement techniques used in this study as well (Table 4). From S0 to S3, there is a clear

517 trend in decreasing surface diameter, $\delta$, and increasing thickness, $t$. Nevertheless, the AsFlFFF results are obtained from measurements with rather low recoveries while the PCS is detecting all aggregates in the dispersion. Consequently, the results presented in Table 4 can only be considered as partly representative of the complete samples due to the low recoveries in the AsFlFFF-measurements. If one considers the dispersions where $\geq 50 \%$ of the mass is recovered (S1 and smaller), the mean disc surface diameter $(\delta)$ of the clay aggregates is decreasing, whereas the thickness $(t)$ is increasing with further fractionation steps. The difference between the dispersion S3 and S3.5 appears only in the thickness of the clay aggregates. As expected, comparable results are obtained for the dispersions S3.5 (obtained after continuous (ultra-)centrifugation steps) and $\mathrm{S} 3.5^{\mathrm{UC}}$ (obtained after one single ultracentrifugation step). Interestingly, the thickness, and thus number of clay sheets, appears slightly higher in presence of FA during the fractionation, which may indicate that the presence of FA could stabilize thicker clay aggregates, i.e. maintain a larger number of 530 stacked clay mineral layers together.

531 In conclusion, the fractionation protocol developed in the present study enables to obtain

532 heterogeneous dispersions of clay aggregates. Assimilating the clay aggregates to discs of 533 surface diameter $\delta$ and thickness $t$, the results indicate presence of aggregates with mean 
surface diameters ranging from $\sim 245 \mathrm{~nm}$ up to $1500 \mathrm{~nm}$ and with mean thicknesses ranging from $\sim 18$ up to $70 \mathrm{~nm}(\sim 14$ to 52 clay layers). In presence of FA during the fractionation, clay aggregates with a surface diameter of $\sim 190 \mathrm{~nm}$ can be isolated, but with a slightly larger thickness $(\sim 63 \mathrm{~nm})$ as those obtained under the same fractionation conditions in absence of FA. The present results would greatly benefit of complementary investigations involving the use of other microscopy techniques like AFM.

\subsubsection{An attempt to estimate the mean number of edge sites}

By approximating clay aggregates to discs of mean diameter $\delta$, estimations of the mean number of edge sites in each clay dispersion were performed. This will be used in an attempt for better interpretation of the data for radionuclides sorption by surface complexation and sorption reversibility (manuscripts in preparation).

Estimations of the number of edge sites are performed according to the work of White and Zelazny (White and Zelazny, 1988) and Tournassat et al. (Tournassat et al., 2003), assuming a clay density of $2.7 \mathrm{~g} / \mathrm{cm}^{3}$, and are presented in Table 5. It is considered that the stacking of clay mineral layers does not change the accessibility to the lateral surfaces, only the interlayer basal surfaces are not accessible.

Table 5: Estimation of the mean number of edge sites for each clay dispersion from PCS- and AsFIFFFdata. The perimeter of a clay stack is noted as $P$ and is calculated by using the clay aggregate disc diameter $\delta$. The clay disc area (A) is calculated by using $\delta$ as the mean diameter of the clay aggregate as well. .

\begin{tabular}{|c|c|c|c|c|c|}
\hline Samples & $\delta(\mathbf{n m})$ & $\begin{array}{c}\text { Ratio (P/A) } \\
\mathbf{n m}^{-1}\end{array}$ & $\mathbf{n}_{\mathbf{A l}} \mathbf{m m o l} / \mathbf{k g}$ & $\mathbf{n}_{\mathbf{S i}} \mathbf{m m o l} / \mathbf{k g}$ & $\begin{array}{c}\mathbf{n}_{\text {Tot }} \mathbf{~ m m o l} / \\
\mathbf{k g}\end{array}$ \\
\hline $\mathbf{S 0}$ & 1496 & 0.0027 & 4.9 & 6.3 & 11.2 \\
\hline $\mathbf{S 1}$ & 940 & 0.0042 & 7.8 & 10.0 & 17.8 \\
\hline S2 & 500 & 0.0080 & 14.7 & 18.8 & 33.5 \\
\hline
\end{tabular}




\begin{tabular}{|c|c|c|c|c|c|}
\hline $\mathbf{S 3}$ & 250 & 0.0161 & 29.4 & 37.6 & 67.0 \\
\hline $\mathbf{S 3 . 5}$ & 258 & 0.0152 & 28.4 & 36.3 & 64.7 \\
\hline $\mathbf{S 3 . 5}$ & 246 & 0.0162 & 29.8 & 38.1 & 67.9 \\
\hline $\mathbf{S 3 . 5}$ & & & & & \\
\hline
\end{tabular}

555 The results show variations up to a factor $\sim 8$, but they are only considered as approximations 556 since the aggregate dimensions are underestimated. Taking a regular disc to mimic smectite 557 aggregates does not take into account their convexities and concavities which lead to an 558 increase in their surface area and perimeter. When considering the dispersions with the 559 smaller mean clay size $\left(\mathrm{S} 3.5, \mathrm{~S} 3.5^{\mathrm{UC}}\right.$ and $\left.\mathrm{S} 3.5^{\mathrm{UC}, \mathrm{FA}}\right)$, the results are in agreement with those of

560 Tournassat et al. (Tournassat et al., 2003).

\subsection{Stability studies}

562 Evaluation of the Al-AsFlFFF/ICP-MS fractograms for the montmorillonite fractions reveals

563 broad clay aggregate size distributions that might be constituted by several different clay size

564 fractions (Figure 3). Consequently, it is not surprising that the data obtained from the stability 565 studies are very scattered (Figure 5). Therefore, it becomes challenging to clearly observe the 566 increase in mean particle size which reflects the agglomeration rate (especially for the 567 dispersion S0 which will not be further considered). In addition, one has to consider that the 568 agglomeration behavior of smaller sized particles are probably hidden by the dominant 569 scattered light intensities from larger particles as the PCS preferentially detect those larger 570 sized entities. Nevertheless, the results from the data evaluation are less scattered for the 571 dispersions obtained after several centrifugation steps (S3 and S3.5). 


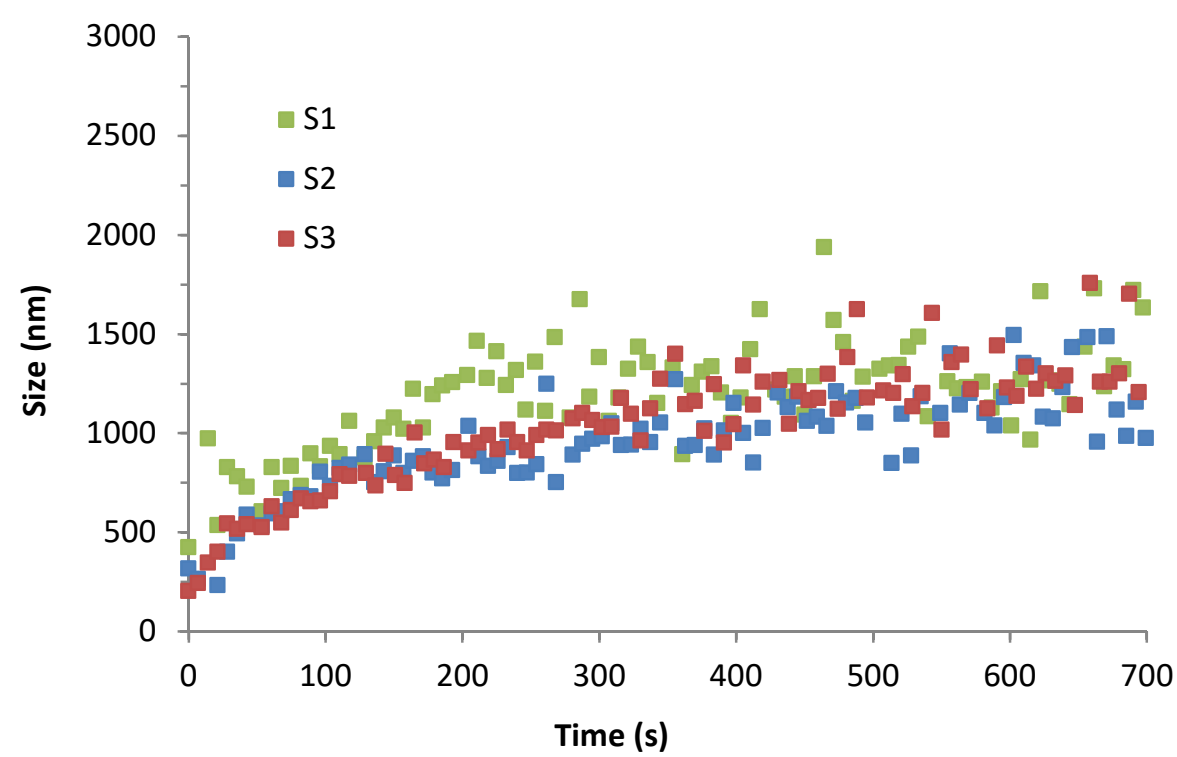

572

573

574

575

576

577

578

579

580

581

582

583

584

585

586

587

Figure 5: Increase in hydrodynamic diameter for three of the montmorillonite dispersions while adding $0.01 \mathrm{M} \mathrm{CaCl}_{2}$ to the dispersions at $\mathrm{pH} 7$.

The calculated stability ratios (W) for all dispersions at $\mathrm{pH} 7$ and for different ionic strengths are presented in Figure 6. The presented $\mathrm{W}$-values are obtained for an ionic strength set by addition of the electrolytes $\mathrm{NaCl}, \mathrm{CaCl}_{2}$ or $\mathrm{MgCl}_{2}$. As expected, $\mathrm{W}$ decreases with increasing ionic strength. This is clearly seen after addition of $\mathrm{NaCl}$ (Figure 6a) and is consistent with the DLVO-theory. Furthermore, addition of $\mathrm{CaCl}_{2}$ and $\mathrm{MgCl}_{2}$ affects the montmorillonite particles more strongly than addition of the same ionic strength set by $\mathrm{NaCl}$ since the lowest concentrations of $\mathrm{CaCl}_{2}$ and $\mathrm{MgCl}_{2}$ are already enough to destabilize the montmorillonite particles (Figure 6b and 6c), as expected from previous studies (Schudel et al., 1997). This is in line with the well-known Shulze-Hardy rule (Overbeek, 1980). The decrease in stability ratio in presence of divalent cations is partly explained by specific interaction of divalent cations as previously reported in the literature (French et al., 2009; Keiding and Nielsen, 1997; Norrfors, 2015; Oncsik et al., 2014; Pantina and Furst, 2006). 
588 According to the DVLO-theory, considering the interaction between two identical spherical 589 particles, the calculated Van der Waals (VdW)-forces increase for increasing particle size 590 (Ottewill and Shaw, 1966; Reerink and Overbeek, 1954; Shah et al., 2002). However, it has 591 been found previously that in a system of high ionic strength, i.e. where no electrostatic 592 repulsions are present, the kinetic energy dominates over the VdW-forces and the 593 agglomeration rate constants of spherical latex particles are therefore independent of the 594 particle size (Norrfors, 2015). Even though clay aggregates are known to have different 595 shapes and compositions than the latex particles present in the previous study (Norrfors, 596 2015), the domination of the kinetic energy can be one explanation of the absence of 597 significant differences between the colloidal dispersions in this study (Figure 6). The absence 598 of particle size dependency on the stability ratios is further in agreement with previous studies 599 (Behrens et al., 2000; Ottewill and Shaw, 1966) but once again, one should have in mind that 600 PCS measurements in polydisperse dispersions favour larger sized particles and thereby 601 hiding the agglomeration behaviour of the smaller sized ones. Previous studies of 602 polydisperse dispersions (Chang and Wang, 2004; Jia and Iwata, 2010) indicate that their 603 stability ratio is smaller than for a mono disperse system, which may be seen in this study. 

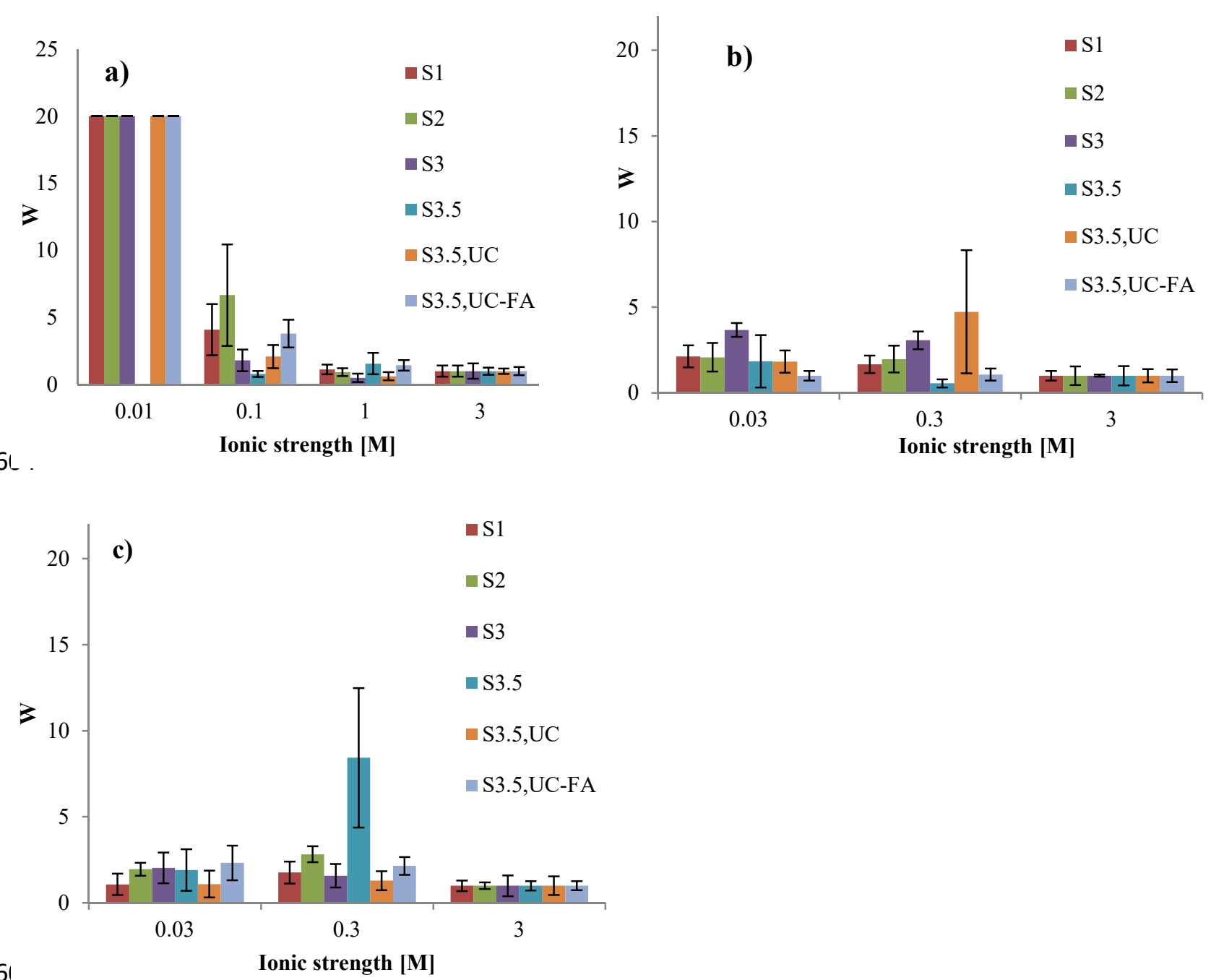

606

607 Figure 6: Stability ratios for the colloidal dispersions after addition of a) $\mathrm{NaCl}_{\text {b) }} \mathrm{CaCl}_{2}$ or c) $\mathrm{MgCl}_{2}$, at $\mathrm{pH}$ 608 7. Infinity is set to 20 in the figures.

609

610 Finally, no significant differences in stability are observed in presence or absence of FA in the

611 dispersions. Previous studies present a stabilization of the clay particles in presence of FA 612 (Kretzschmar et al., 1998) and notice that the stabilization properties of FA decreases with 613 increasing $\mathrm{pH}$, due to the lower FA adsorption to clay surfaces. In the present study of 614 agglomeration, coursed by addition of $\mathrm{CaCl}_{2}$, the relative high concentration of divalent ions, 
$615 \mathrm{Ca}^{2+}$, induced agglomeration with the same agglomeration rate in both presence and absence 616 of FA.

\section{Conclusions}

- A protocol to obtain montmorillonite colloid dispersions with different size fractions is developed in this study. It is based on a sedimentation step followed by sequential or direct (ultra-)centrifugation.

- Montmorillonite aggregates of same composition are proved to be present in the different dispersions as concluded from both the chemical analysis and the XRD results. Calcium is associated to the clay particles as natural calcite or due to the fast ionic exchange processes arising under the present experimental conditions. An instant release of sodium and sulfate occurs when the bentonite is suspended in the SGW. This is explained by dissolution of gypsum or/and celestite naturally present in the unpurified MX-80 bentonite.

- Mean equivalent sphere diameters (EDS) values obtained by different methods agree when normalized to comparable physical properties, leading to a mean hydrodynamic size of the clay aggregates from $\sim 960 \mathrm{~nm}$ down to $\sim 85 \mathrm{~nm}$. Nevertheless, after applying mathematical treatments, the differences recorded in the initial data between the AsFlFFF (giving the Stokes' diameter) and the PCS (giving a frictional translatory diffusion diameter) are used to estimate the mean diameter $\delta$ and the thickness $t$ of the clay aggregates in the different dispersions after approximating those to regular discshaped aggregates consisting of stacked clay mineral layers. According to our calculation, $\delta$ varies from $1.5 \mu \mathrm{m}$ down to $\sim 190 \mathrm{~nm}$ and $t$ lies in the range of 18 to 70 $\mathrm{nm}$. The number of sheets (clay mineral layers) is determined by dividing the thickness $t$ by $1.3 \mathrm{~nm}$ (thickness of one single clay layer in basal spacing). The 
corresponding axial (or aspect) ratios $(\rho=\delta / t)$ calculated in this study agree well with literature data. Further calculations, based on literature, give an estimation of the number of edge sites in each clay dispersion. These data will be used in an attempt to model the results from radionuclides sorption experiments performed by using these clay dispersions (manuscript in preparation).

- The stability of montmorillonite is higher in $\mathrm{NaCl}$ solution than in $\mathrm{CaCl}_{2}$ and $\mathrm{MgCl}_{2}$ for the same ionic strength, which is in line with the Schulze-Hardy rule. In addition, the stability ratio is independent on the colloidal size initially present.

\section{Acknowledgements}

The Swedish Nuclear Fuel and Waste Management Co. (SKB) is gratefully acknowledged for generous financial support. This work is a part of the project CP-BELBaR Fission 2010-1.1.1. This work has been supported by the European FP7 TALISMAN project, JRP $\mathrm{n}^{\mathrm{o}}$ TALI-C0210.

\section{References}

Ali, S., Bandyopadhyay, R., 2013. Use of Ultrasound Attenuation Spectroscopy to Determine the Size Distribution of Clay Tactoids in Aqueous Suspensions. Langmuir 29, 12663-12669.

Baalousha, M., Kammer, F.D., Motelica-Heino, M., Le Coustumer, P., 2005. 3D characterization of natural colloids by FlFFF-MALLS-TEM. Anal Bioanal Chem 383, 549556.

Baalousha, M., Kammer, F.V.D., Motelica-Heino, M., Hilal, H.S., Le Coustumer, P., 2006. Size fractionation and characterization of natural colloids by flow-field flow fractionation coupled to multi-angle laser light scattering. Journal of Chromatography A 1104, 272-281. 
661 Beckett, R., Murphy, D., Tadjiki, S., Chittleborough, D.J., Calvin Giddings, J., 1997. 662 Determination of thickness, aspect ratio and size distributions for platey particles using 663 sedimentation field-flow fractionation and electron microscopy. Colloids and Surfaces A: 664 Physicochemical and Engineering Aspects 120, 17-26.

665 Behrens, S.H., Christl, D.I., Emmerzael, R., Schurtenberger, P., Borkovec, M., 2000. 666 Charging and Aggregation Properties of Carboxyl Latex Particles: Experiments versus 667 DLVO Theory. Langmuir 16, 2566-2575.

668 Bergaya, F., Theng, B.K.G., Lagaly, G., 2006. Handbook of Clay Science.

669 Bessho, K., Degueldre, C., 2009. Generation and sedimentation of colloidal bentonite 670 particles in water. Applied Clay Science 43, 253-259.

671 Bhatia, M.P., Das, S.B., Longnecker, K., Charette, M.A., Kujawinski, E.B., 2010. Molecular 672 characterization of dissolved organic matter associated with the Greenland ice sheet. 673 Geochim. Cosmochim. Acta 74, 3768-3784.

674 Bouby, M., Finck, N., Geckeis, H., 2012. Flow field-flow fractionation (FlFFF) coupled to 675 sensitive detection techniques: a way to examine radionuclide interactions with nanoparticles. 676 Mineralogical Magazine 76, 2709-2721.

677 Bouby, M., Geckeis, H., Geyer, F.W., 2008. Application of asymmetric flow field-flow 678 fractionation (AsFlFFF) coupled to inductively coupled plasma mass spectrometry (ICPMS) 679 to the quantitative characterization of natural colloids and synthetic nanoparticles. Anal 680 Bioanal Chem 392, 1447-1457.

681 Bouby, M., Geckeis, H., Lutzenkirchen, J., Mihai, S., Schafer, T., 2011. Interaction of 682 bentonite colloids with $\mathrm{Cs}, \mathrm{Eu}, \mathrm{Th}$ and $\mathrm{U}$ in presence of humic acid: A flow field-flow 683 fractionation study. Geochim. Cosmochim. Acta 75, 3866-3880. 
Bouby, M., Geckeis, H., Manh, T.N., Yun, J.-I., Dardenne, K., Schäfer, T., Walther, C., Kim, J.-I., 2004. Laser-induced breakdown detection combined with asymmetrical flow field-flow fractionation: application to iron oxi/hydroxide colloid characterization. Journal of Chromatography A 1040, 97-104.

Bowen, P., 2002. Particle Size Distribution Measurement from Millimeters to Nanometers and from Rods to Platelets. Journal of Dispersion Science and Technology 23, 631-662.

Bowen, P., Sheng, J., Jongen, N., 2002. Particle size distribution measurement of anisotropic_-particles cylinders and platelets_practical examples. Powder Technology 128, 256-261.

Bradbury, M.H., Baeyens, B., 2002. Porewater chemistry in compacted re-saturated MX-80 bentonite: Physico-chemical characterisation and geochemical modelling PSI Bericht Nr. 02$10,28$.

Bro, R., De Jong, S., 1997. A fast non-negativity-constrained least squares algorithm. Journal of chemometrics 11, 393-401.

Brown, G.H., 2002. Glacier meltwater hydrochemistry. Applied Geochemistry 17, 855-883.

Cadene, A., Durand-Vidal, S., Turq, P., Brendle, J., 2005. Study of individual Namontmorillonite particles size, morphology, and apparent charge. Journal of Colloid and Interface Science 285, 719-730.

Chang, Y.-I., Wang, M.-C., 2004. Heteroflocculation of equal numbers of different sized colloidal particles in binary dispersions under enhanced gravity forces. Colloids and Surfaces A: Physicochemical and Engineering Aspects 251, 75-86. 
Czigány, S., Flury, M., Harsh, J.B., 2005. Colloid Stability in Vadose Zone Hanford Sediments. Environmental Science \& Technology 39, 1506-1512.

Darbha, G.K., Schäfer, T., Heberling, F., Lüttge, A., Fischer, C., 2010. Retention of Latex Colloids on Calcite as a Function of Surface Roughness and Topography. Langmuir 26, 47434752.

Ferrage, E., Lanson, B., Sakharov, B.A., Drits, V.A., 2005. Investigation of smectite hydration properties by modeling experimental X-ray diffraction patterns: Part I. Montmorillonite hydration properties. Am. Miner. 90, 1358-1374.

Filby, A., Plaschke, M., Geckeis, H., Fanghänel, T., 2008. Interaction of latex colloids with mineral surfaces and Grimsel granodiorite. Journal of Contaminant Hydrology 102, 273-284.

Finck, N., Bouby, M., Dardenne, K., Geckeis, H., 2012. Characterization of Eu(III) coprecipitated with and adsorbed on hectorite: from macroscopic crystallites to nanoparticles. Mineralogical Magazine 76, 2723-2740.

French, R.A., Jacobson, A.R., Kim, B., Isley, S.L., Penn, R.L., Baveye, P.C., 2009. Influence of Ionic Strength, pH, and Cation Valence on Aggregation Kinetics of Titanium Dioxide Nanoparticles. Environmental Science \& Technology 43, 1354-1359.

Furukawa, Y., Watkins, J.L., 2012. Effect of Organic Matter on the Flocculation of Colloidal Montmorillonite: A Modeling Approach. J. Coast. Res. 28, 726-737.

Gallego-Urrea, J., Hammes, J., Cornelis, G., Hassellöv, M., 2014. Multimethod 3D characterization of natural plate-like nanoparticles: shape effects on equivalent size measurements. J. Nanopart. Res. 16, 1-17. 
Gantenbein, D., Schoelkopf, J., Matthews, G.P., Gane, P.A.C., 2011. Determining the size distribution-defined aspect ratio of platy particles. Applied Clay Science 53, 544-552.

Gao, S.A., Walker, W.J., Dahlgren, R.A., Bold, J., 1997. Simultaneous sorption of Cd, Cu, $\mathrm{Ni}, \mathrm{Zn}, \mathrm{Pb}$, and $\mathrm{Cr}$ on soils treated with sewage sludge supernatant. Water Air and Soil Pollution 93, 331-345.

Gaucher, E.C., Tournassat, C., Pearson, F.J., Blanc, P., Crouzet, C., Lerouge, C., Altmann, S., 2009. A robust model for pore-water chemistry of clayrock. Geochim. Cosmochim. Acta 73, 6470-6487.

Geckeis, H., Schäfer, T., Hauser, W., Rabung, T., Missana, T., Degueldre, C., Möri, A., Eikenberg, J., Fierz, T., Alexander, W.R., 2004. Results of the colloid and radionuclide retention experiment (CRR) at the Grimsel Test Site (GTS), Switzerland - impact of reaction kinetics and speciation on radionuclide migration. Radiochim. Acta 92, 765-774.

Gélinas, V., Vidal, D., 2010. Determination of particle shape distribution of clay using an automated AFM image analysis method. Powder Technology 203, 254-264.

Hauser, W., Geckeis, H., Kim, J.I., Fierz, T., 2002. A mobile laser-induced breakdown detection system and its application for the in situ-monitoring of colloid migration. Colloids and Surfaces A: Physicochemical and Engineering Aspects 203, 37-45.

Holthoff, H., Egelhaaf, S.U., Borkovec, M., Schurtenberger, P., Sticher, H., 1996. Coagulation Rate Measurements of Colloidal Particles by Simultaneous Static and Dynamic Light Scattering. Langmuir 12, 5541-5549.

Hu, J., Xu, D., Chen, L., Wang, X.K., 2009. Characterization of MX-80 bentonite and its sorption of radionickel in the presence of humic and fulvic acids. J. Radioanal. Nucl. Chem. 279, 701-708. 
Huber, F., Enzmann, F., Wenka, A., Bouby, M., Dentz, M., Schäfer, T., 2012. Natural microscale heterogeneity induced solute and nanoparticle retardation in fractured crystalline rock. Journal of Contaminant Hydrology 133, 40-52.

Huber, F., Heck, S., Truche, L., Bouby, M., Brendlé, J., Höss, P., Schäfer, T., 2014. Radionuclide desorption kinetics on synthetic $\mathrm{Zn} / \mathrm{Ni}$-labelled montmorillonite nanoparticles. Geochim. Cosmochim. Acta Just accepted.

Jennings, B.R., 1993. Size and thickness measurement of polydisperse clay samples. Clay Minerals 28, 485-494.

Jennings, B.R., Parslow, K., 1988. Particle Size Measurement: The Equivalent Spherical Diameter. Proceedings of the Royal Society of London. A. Mathematical and Physical Sciences 419, 137-149.

Jia, J., Iwata, S., 2010. Nonequilibrium structure of primary particles in colloidal bidispersion. Colloid Polym Sci 288, 1485-1493.

Kammer, F.v.d., Baborowski, M., Friese, K., 2005. Field-flow fractionation coupled to multiangle laser light scattering detectors: Applicability and analytical benefits for the analysis of environmental colloids. Analytica Chimica Acta 552, 166-174.

Karnland, O., Olsson, S., Nilsson, U., 2006. Mineralogy and sealing properties of various bentonites and smectite-rich clay materials. SKB internal report TR-06-30.

Keiding, K., Nielsen, P.H., 1997. Desorption of organic macromolecules from activated sludge: Effect of ionic composition. Water Research 31, 1665-1672. 
Kretzschmar, R., Holthoff, H., Sticher, H., 1998. Influence of pH and Humic Acid on Coagulation Kinetics of Kaolinite: A Dynamic Light Scattering Study. Journal of Colloid and Interface Science 202, 95-103.

Kunkel, W.B., 1948. Magnitude and Character of Errors Produced by Shape Factors in Stokes\&apos; Law Estimates of Particle Radius. Journal of Applied Physics 19, 1056-1058.

Lee, S.Z., Chang, L., Chen, C.M., Tsai, Y.I., Liu, M.C., 2001. Predicting soil-water partition coefficients for $\mathrm{Hg}$ (II) from soil properties. Water Science and Technology 43, 187-196.

Liu, L., Moreno, L., Neretnieks, I., 2008. A Novel Approach to Determine the Critical Coagulation Concentration of a Colloidal Dispersion with Plate-like Particles. Langmuir 25, 688-697.

Macdonald, D.D., Sharifi-Asl, S., 2011. Is Copper Immune to Corrosion When in Contact With Water and Aqueous Solutions? Swedish Radiation Safety Authourity, SSM, Report 2011:09.

Meier, L.P., Kahr, G., 1999. Determination of the cation exchange capacity (CEC) of clay minerals using the complexes of copper(II) ion with triethylenetetramine and tetraethylenepentamine. Clay Clay Min. 47, 386-388.

Meunier, A., 2005. Clays. Springer-Verlag Berlin Heidelberg.

Missana, T., Alonso, Ú., Turrero, M.J., 2003. Generation and stability of bentonite colloids at the bentonite/granite interface of a deep geological radioactive waste repository. Journal of Contaminant Hydrology 61, 17-31.

Möri, A., Alexander, W.R., Geckeis, H., Hauser, W., Schafer, T., Eikenberg, J., Fierz, T., Degueldre, C., Missana, T., 2003. The colloid and radionuclide retardation experiment at the 
Grimsel Test Site: influence of bentonite colloids on radionuclide migration in a fractured rock. Colloids and Surfaces a-Physicochemical and Engineering Aspects 217, 33-47.

Nakamaru, Y., Uchida, S., 2008. Distribution coefficients of tin in Japanese agricultural soils and the factors affecting tin sorption behavior. Journal of Environmental Radioactivity 99, 1003-1010.

Norrfors, K.K., 2015. Stability and sorption capacity of montmorillonite colloids: Investigation of size fractional differences and effects of $\gamma$-irradiation, KTH Applied Physical Chemistry. KTH Royal Institute of Technology, Stockholm, Sweden.

Norrfors, K.K., Bouby, M., Marsac, R., Heck, S., Schäfer, T., Geckeis, H., Wold, S., 2015. Montmorillonite colloids. II: The Dependency of Colloidal size on the Radionuclide Sorption Capacities Manuscript in preparation.

Oliver, I.W., Merrington, G., McLaughlin, M.J., 2006. Copper partitioning among mineral and organic fractions in biosolids. Environmental Chemistry 3, 48-52.

Oncsik, T., Trefalt, G., Csendes, Z., Szilagyi, I., Borkovec, M., 2014. Aggregation of Negatively Charged Colloidal Particles in the Presence of Multivalent Cations. Langmuir 30, $733-741$.

Ottewill, R.H., Shaw, J.N., 1966. Stability of monodisperse polystyrene latex dispersions of various sizes. Discussions of the Faraday Society 42, 154-163.

Overbeek, J.T.G., 1980. The Rule of Schulze and Hardy. Pure Appl. Chem. 52, No. 5, 11511161.

Pabst, W., Berthold, C., 2007. A Simple Approximate Formula for the Aspect Ratio of Oblate Particles. Particle \& Particle Systems Characterization 24, 458-463. 
813 Pantina, J.P., Furst, E.M., 2006. Colloidal Aggregate Micromechanics in the Presence of 814 Divalent Ions. Langmuir 22, 5282-5288.

815 Perret, D., Newman, M.E., Nègre, J.-C., Chen, Y., Buffle, J., 1994. Submicron particles in the 816 rhine river-I. Physico-chemical characterization. Water Research 28, 91-106.

817 Plaschke, M., Schäfer, T., Bundschuh, T., Ngo Manh, T., Knopp, R., Geckeis, H., Kim, J.I., 818 2001. Size Characterization of Bentonite Colloids by Different Methods. Analytical 819 Chemistry $73,4338-4347$.

820 Reerink, H., Overbeek, J.T.G., 1954. The rate of coagulation as a measure of the stability of 821 silver iodide sols. Discussions of the Faraday Society.

822 Schimpf, M., Caldwell, K., Giddings, J.C., 2000. Field flow fractionation handbook.

823 Schramm, L.L., Kwak, J.C.T., 1982a. Influence of exchangeable cation composition on the 824 size and shape of montmorillonite particles in dilute suspension. Clay Clay Min. 30, 40-48.

825 Schramm, L.L., Kwak, J.C.T., 1982b. Interactions in clay suspensions: The distribution of 826 ions in suspension and the influence of tactoid formation. Colloids and Surfaces 4, 43-60.

827 Schudel, M., Behrens, S.H., Holthoff, H., Kretzschmar, R., Borkovec, M., 1997. Absolute 828 Aggregation Rate Constants of Hematite Particles in Aqueous Suspensions: A Comparison of 829 Two Different Surface Morphologies. Journal of Colloid and Interface Science 196, 241-253.

830 Schäfer, T., Huber, F., Seher, H., Missana, T., Alonso, U., Kumke, M., Eidner, S., Claret, F., 831 Enzmann, F., 2012. Nanoparticles and their influence on radionuclide mobility in deep 832 geological formations. Applied Geochemistry 27, 390-403. 
833 Shah, P.S., Holmes, J.D., Johnston, K.P., Korgel, B.A., 2002. Size-selective dispersion of 834 dodecanethiol-coated nanocrystals in liquid and supercritical ethane by density tuning. J. 835 Phys. Chem. B 106, 2545-2551.

SKB, 2010. Design and production of the KBS-3 repository. SKB internal report TR-10-12.

837 Sposito, G., 1992. The diffuse-ion swarm near smectite particles suspended in 1:1 electrolyte 838 solutions: modified Gouy-Chapman theory and quasicrystal formation., in: Güven, N., 839 Pollastro, R.M. (Eds.), CMS Workshop Lectures 4, Clay water interface and its rheological 840 implications. Clay minerals society, pp. 127-156.

841 Stumm, W., 1993. Aquatic colloids as chemical reactants: surface structure and reactivity. 842 Colloids and Surfaces A: Physicochemical and Engineering Aspects 73, 1-18.

843 Tournassat, C., Bizi, M., Braibant, G., Crouzet, C., 2011. Influence of montmorillonite tactoid 844 size on $\mathrm{Na}-\mathrm{Ca}$ cation exchange reactions. Journal of Colloid and Interface Science 364, 443845454

Tournassat, C., Neaman, A., Villiéras, F., Bosbach, D., Charlet, L., 2003. Nanomorphology of montmorillonite particles: Estimation of the clay edge sorption site density by low-pressure gas adsorption and AFM observations. Am. Miner. 88, 1989-1995.

Vahlund, F., Hermansson, H., 2006. A direct numerical approach to solving the transport equations for radionuclide transport in fractured rock. SKB internal report R-04-50. minerals determined from conductometric titrations. Clay Minerals 49, 495-498.

853 Veghte, D.P., Freedman, M.A., 2014. Facile Method for Determining the Aspect Ratios of 
855 White, G.N., Zelazny, L.W., 1988. Analysis and implications of the edge structure of 856 dioctahedral phyllosilicates. Clay Clay Min. 36, 141-146.

857 Vieno, T., Ikonen, A.T.K., 2005. Plan for Safety Case of Spent Fuel Repository at Olkiluoto, 858 POSIVA Report 2005-1. POSIVA.

859 Wold, S., 2010. Sorption of prioritized elements on montmorillonite colloids and their 860 potential to transport radionuclides. SKB internal report TR-10-20.

861 Wolf, M., Buckau, G., Geyer, S., 2004. Isolation and characterisation of new batches of 862 GoHy-573 humic and fulvic acids., in: ed., G.B. (Ed.), Humic substances in performance 863 assessment of nuclear waste disposal: Actinide and iodine migration in the far-field. 864 Wissenschaftliche Berichte FZKA 6969, Forschungszentrum Karlsruhe, pp. 111-124.

865 Vuorinen, U., Snellman, M., 1998. Finnish reference waters for solubility, sorption and 866 diffusion studies Posiva Working Report 98-61 17-19. 